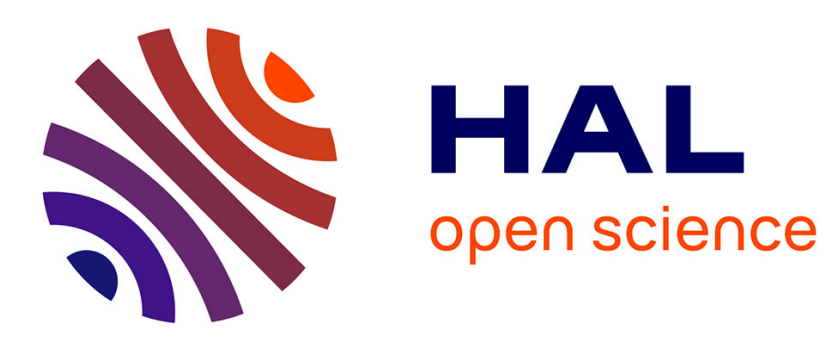

\title{
Fluoroalkyl Radical Generation by Homolytic Bond Dissociation in Pentacarbonylmanganese Derivatives
}

Roberto Morales-Cerrada, Christophe Fliedel, Jean-Claude Daran, Florence Gayet, Vincent Ladmiral, Bruno Ameduri, Rinaldo Poli

\section{- To cite this version:}

Roberto Morales-Cerrada, Christophe Fliedel, Jean-Claude Daran, Florence Gayet, Vincent Ladmiral, et al.. Fluoroalkyl Radical Generation by Homolytic Bond Dissociation in Pentacarbonylmanganese Derivatives. Chemistry - A European Journal, 2019, 25 (1), pp.296-308. 10.1002/chem.201804007. hal-01983372

\section{HAL Id: hal-01983372 \\ https://hal.science/hal-01983372}

Submitted on 30 Oct 2020

HAL is a multi-disciplinary open access archive for the deposit and dissemination of scientific research documents, whether they are published or not. The documents may come from teaching and research institutions in France or abroad, or from public or private research centers.
L'archive ouverte pluridisciplinaire HAL, est destinée au dépôt et à la diffusion de documents scientifiques de niveau recherche, publiés ou non, émanant des établissements d'enseignement et de recherche français ou étrangers, des laboratoires publics ou privés. 


\title{
Fluoroalkyl radical generation by homolytic bond dissociation in pentacarbonylmanganese derivatives
}

\author{
Roberto Morales-Cerrada, ${ }^{[a, b]}$ Christophe Fliedel, ${ }^{[a]}$ Jean-Claude Daran, ${ }^{[a]}$ Florence Gayet, ${ }^{[a]}$ Vincent \\ Ladmiral, ${ }^{[b]}$ Bruno Améduri, ${ }^{[b] *}$ and Rinaldo Poli[ ${ }^{[a] *}$
}

Abstract: Thermal decarbonylation of the acyl compounds $\left[\mathrm{Mn}(\mathrm{CO})_{5}\left(\mathrm{COR}_{\mathrm{F}}\right)\right]\left(\mathrm{R}_{\mathrm{F}}=\mathrm{CF}_{3}, \mathbf{1} ; \mathrm{CHF}_{2}, \mathbf{2} ; \mathrm{CH}_{2} \mathrm{CF}_{3}, \mathbf{3} ; \mathrm{CF}_{2} \mathrm{CH}_{3}, 4\right)$ yields the corresponding alkyl derivatives $\left[\mathrm{Mn}(\mathrm{CO})_{5}\left(\mathrm{R}_{\mathrm{F}}\right)\right]\left(\mathrm{R}_{\mathrm{F}}=\mathrm{CF}_{3}, \mathbf{5} ; \mathrm{CHF}_{2}\right.$, 6; $\left.\mathrm{CH}_{2} \mathrm{CF}_{3}, 7 ; \mathrm{CF}_{2} \mathrm{CH}_{3}, \mathbf{8}\right)$. Compounds 3, 4, 7 and 8 have not been previously reported. All compounds, except 8 which could not be obtained in a pure state, were fully characterized by analytical and spectroscopic methods, as well as by single-crystal X-ray diffraction for $1,2,4,5,6$ and 7 . The solution IR characterization in the CO stretching region, with the assistance of DFT calculations, has allowed the assignment of several weak bands to vibrations of the $\left[\mathrm{Mn}\left({ }^{12} \mathrm{CO}\right){ }_{4}\left(e q-{ }^{13} \mathrm{CO}\right)\left(\mathrm{R}_{\mathrm{F}}\right)\right]$ and $\left[\mathrm{Mn}\left({ }^{12} \mathrm{CO}\right)_{4}\left(a x^{-13} \mathrm{CO}\right)\left(\mathrm{R}_{\mathrm{F}}\right)\right]$ isotopomers and a ranking of the $\mathrm{R}_{\mathrm{F}}$ donor power in the order $\mathrm{CF}_{3}<\mathrm{CHF}_{2}<\mathrm{CH}_{2} \mathrm{CF}_{3}$ $\sim \mathrm{CF}_{2} \mathrm{CH}_{3}$. The homolytic $\mathrm{Mn}-\mathrm{R}_{\mathrm{F}}$ bond cleavage in $\left[\mathrm{Mn}(\mathrm{CO})_{5}\left(\mathrm{R}_{\mathrm{F}}\right)\right]$, carried out at various temperatures for compounds 5, 6 and 7 under saturation conditions, with trapping of the generated $R_{F}$ radicals by tris(trimethylsilyl)silane (TTMSS, 10 equiv), has yielded activation parameters $\Delta H^{\ddagger}$ and $\Delta S^{\ddagger}$ that are believed to represent close estimates of the homolytic bond dissociation thermodynamic parameters. The values $\left(\Delta H^{\ddagger}=53.8 \pm 3.5(5), 46.3 \pm 1.6(6), 50.6 \pm 0.8\right.$ (7) kcal $/ \mathrm{mol} ; \Delta S^{\ddagger}=66.0 \pm 9.5$ (5), $55.8 \pm 4.7$ (6), 65.4 \pm 2.2 (7) $\mathrm{cal} \mathrm{mol}^{-1}$ $\mathrm{K}^{-1}$ ) are in close agreement with the results of a recent DFT study ( $\mathrm{J}$. Organomet. Chem. 2018, 864, 12-18). The ability of these complexes to undergo homolytic $\mathrm{Mn}-\mathrm{R}_{\mathrm{F}}$ bond cleavage was further demonstrated by the observation that compound $\mathbf{5}$ (the member with the strongest $\mathrm{Mn}-\mathrm{R}_{\mathrm{F}}$ bond) initiates the radical polymerization of vinylidene fluoride $\left(\mathrm{CH}_{2}=\mathrm{CF}_{2}\right.$, VDF), to produce poly(vinylidene fluoride) (PVDF) in good yields by either thermal $\left(100^{\circ} \mathrm{C}\right)$ or photochemical (UV or visible light) activation.

\section{Introduction}

Alkylpentacarbonylmanganese $(\mathrm{I})$ are landmark compounds in organometallic chemistry, first prepared by Coffield in $1957^{[1]}$ and studied as models for the ubiquitous "migratory insertion" reaction leading to acyl derivatives, ${ }^{[2]}$ which is a fundamental step in many catalytic cycles. ${ }^{[3]}$ Among them, those containing a fluoroalkyl group have received special attention because of their enhanced

[a] Mr. R. Morales Cerrada, Dr. C. Fliedel, Dr. J.-C. Daran, Dr. F. Gayet, Prof. R. Poli

CNRS, LCC (Laboratoire de Chimie de Coordination)

Université de Toulouse, UPS, INPT

205 route de Narbonne, BP 44099, F-31077 Toulouse Cedex 4, France.

E-mail: rinaldo.poli@Icc-toulouse.fr

[b] Mr. R. Morales Cerrada, Dr. V. Ladmiral, Dr. B. Améduri ICGM

Univ Montpellier, CNRS, ENSCM

Place Eugène Bataillon, 34095 Montpellier, France.

E-mail: bruno.ameduri@enscm.fr

Supporting information for this article is given via a link at the end of the document

thermal stability. Contrary to simple alkylpentacarbonylmanganese(I) compounds, which are readily accessible by nucleophilic substitution of the halide in $\mathrm{R}-\mathrm{X}$ by $\left[\mathrm{Mn}(\mathrm{CO})_{5}\right]^{-}$, the analogous derivatives with fluorine-containing alkyl ligands are not accessible in this manner because the inverted polarity of the $\mathrm{C}-\mathrm{X}$ bond leads instead to the formation of $\left[(\mathrm{CO})_{5} \mathrm{MnX}\right]$ with release of $R_{F}{ }^{-}$, with $\left[\mathrm{Mn}_{2}(\mathrm{CO})_{10}\right.$ ] and $\mathrm{R}_{\mathrm{F}}-\mathrm{R}_{\mathrm{F}}$ resulting from further secondary reactions. ${ }^{[4]}$ However, this obstacle can be overcome by carrying out the nucleophilic substitution on the acyl chloride, $\mathrm{R}_{\mathrm{F}} \mathrm{COCl}$, or the corresponding anhydride, to obtain an acyl intermediate $\left[(\mathrm{CO})_{5} \mathrm{Mn}\left(\mathrm{COR}_{\mathrm{F}}\right)\right]$, which can then be thermally decarbonylated. Thus, trifluoroacetylpentacarbonylmanganese(I), $\left[(\mathrm{CO})_{5} \mathrm{Mn}\left(\mathrm{COCF}_{3}\right)\right]$, resulting from the addition of $\mathrm{Na}\left[\mathrm{Mn}(\mathrm{CO})_{5}\right]$ to either trifluoroacetyl chloride ${ }^{[5]}$ or trifluoroacetic anhydride, ${ }^{[4]}$ was used to access $\left[(\mathrm{CO})_{5} \mathrm{Mn}\left(\mathrm{CF}_{3}\right)\right]$. Other $\left[(\mathrm{CO})_{5} \mathrm{Mn}\left(\mathrm{R}_{\mathrm{F}}\right)\right]$ complexes have also been reported with $\mathrm{R}_{\mathrm{F}}=\mathrm{CFH}_{2},{ }^{[6]} \mathrm{CF}_{2} \mathrm{H},{ }^{[6]}$ and $\mathrm{C}_{n} \mathrm{~F}_{2 n+1}$ (n $=1-4,6) \cdot{ }^{[7]}$

These complexes do not appear to have found direct use in catalysis, whereas many other organomanganese complexes are now intensively investigated as precatalysts for various transformations such as hydrosilylation, ${ }^{[8]}$ dehydrogenative coupling, ${ }^{[8 c, 9]} \mathrm{C}-\mathrm{H}^{[10]}$ and $\mathrm{C}-\mathrm{F}^{[11]}$ activation, etc. However, the possible implication of alkylpentacarbonylmanganese(I) systems with fluorinated alkyl chains in reversible-deactivation radical polymerization (RDRP) has recently been mentioned in contributions by Asandei et al., ${ }^{[12]}$ who described a beneficial role of $\left[\mathrm{Mn}_{2}(\mathrm{CO})_{10}\right]$ on the polymerization of vinylidene fluoride (VDF, $\mathrm{CH}_{2}=\mathrm{CF}_{2}$ ) by the iodine transfer polymerization (ITP) controlling method. In this polymerization technique, most of the chains at any given time reside in an iodine-capped dormant form, PVDF-I, and are reversibly reactivated by a rapid degenerative exchange with the active radical chains, PVDF', which insures a controlled growth by the degenerative transfer protocol. ${ }^{[13]}$

The radical polymerization of VDF produces two different types of chain ends, head $(\mathrm{H})$ and tail $(\mathrm{T})$, following the regular head-totail (dominant) monomer addition (PVDF- $\mathrm{CH}_{2} \mathrm{CF}_{2}{ }^{\circ}$ or $\mathrm{PVDF}_{\mathrm{H}}{ }^{\circ}$ ) and the inverted head-to-head monomer addition $\left(\mathrm{PVDF}^{-} \mathrm{CF}_{2} \mathrm{CH}_{2}{ }^{\cdot}\right.$ or $\mathrm{PVDF}_{\mathrm{T}}{ }^{\circ}$ ), respectively. The proportion of inverted monomer additions is only $3.5-6 \%$ under typical polymerization conditions, ${ }^{[14]}$ but this defect is sufficient to limit the efficiency of ITP because the PVDF $_{T}-1$ dormant chains are less easily reactivated, accumulate during the polymerization so that the control is eventually lost. ${ }^{[15]}$ Carrying out the polymerization in the presence of $\left[\mathrm{Mn}_{2}(\mathrm{CO})_{10}\right]$ and under visible light irradiation led to the reactivation of both dormant species. This was attributed to the ability of $\left[(\mathrm{CO})_{5} \mathrm{Mn}^{*}\right]$, produced by photolytic $\mathrm{Mn}-\mathrm{Mn}$ bond cleavage, to abstract an iodine atom from the dormant chain ends, including from the more recalcitrant $\mathrm{PVDF}_{\mathrm{T}}-\mathrm{I}$, to form $\left[(\mathrm{CO})_{5} \mathrm{Mnl}\right]$ and regenerate the reactive radical chain. ${ }^{[12]}$ In these contributions, the possible direct interaction between $\left[(\mathrm{CO})_{5} \mathrm{Mn}{ }^{\circ}\right]$ and the growing radical chains, leading to the organometallic dormant species $\left[(\mathrm{CO})_{5} \mathrm{Mn}\left(\mathrm{PVDF}_{\mathrm{H}}\right)\right]$ and $\left[(\mathrm{CO})_{5} \mathrm{Mn}\left(\mathrm{PVDF}_{\mathrm{T}}\right)\right]$, was 
also mentioned. However, no evidence for the formation of these species was obtained and it was stated that, if formed, such species may be readily reactivated under the thermal $\left(40^{\circ} \mathrm{C}\right)$ and photochemical (visible light) operating conditions of the polymerization.

Given our interest in organometallic-mediated radical polymerization (OMRP) ${ }^{[16]}$ and in the application of this method to the controlled polymerization of fluorinated monomers, ${ }^{[17]}$ we were interested in probing the possible dissociative activation of the $\mathrm{Mn}-\mathrm{C}$ bond in $\left[(\mathrm{CO})_{5} \mathrm{Mn}\left(\mathrm{R}_{\mathrm{F}}\right)\right]$ under both thermal and photochemical conditions. A recent computational study of all possible fluorinated ethyl derivatives, $\left[(\mathrm{CO})_{5} \mathrm{Mn}\left(\mathrm{CH}_{2-\mathrm{n}} \mathrm{F}_{\mathrm{n}} \mathrm{CH}_{3-\mathrm{m}} \mathrm{F}_{\mathrm{m}}\right)\right]$ $(\mathrm{n}=0-2 ; \mathrm{m}=0-3),{ }^{[18]}$ predicts that the $\mathrm{Mn}-\mathrm{C}$ bond dissociation enthalpies (BDEs) are in the $42-53.5 \mathrm{kcal} / \mathrm{mol}$ range, the value depending on the $C^{\alpha}$ and $C^{\beta} F$ substitution. Thus, a thermal activation of these bonds to produce radicals under mild conditions appears unlikely. In order to learn more about the possible radical generation by $\mathrm{Mn}-\mathrm{C}$ homolytic cleavage in $\left[(\mathrm{CO})_{5} \mathrm{Mn}\left(\mathrm{R}_{\mathrm{F}}\right)\right]$, we have undertaken to experimentally measure the $\mathrm{Mn}-\mathrm{C}$ BDE in these compounds. For this purpose, the previously described derivatives with $\mathrm{R}_{\mathrm{F}}=\mathrm{CF}_{3}$ and $\mathrm{CHF}_{2}$ have been used, as well as new compounds with $\mathrm{R}_{\mathrm{F}}=\mathrm{CH}_{2} \mathrm{CF}_{3}$ and $\mathrm{CF}_{2} \mathrm{CH}_{3}$, the synthesis and characterization of which is reported here for the first time. The two new compounds were targeted because they represent models of the putative head and tail dormant species resulting from the hypothetical chain trapping by [(CO) $\left.{ }_{5} \mathrm{Mn}^{\circ}\right]$. In addition, preliminary observations on the use of $\left[(\mathrm{CO})_{5} \mathrm{Mn}\left(\mathrm{CF}_{3}\right)\right]$ as initiator for the radical polymerization of VDF are reported here.

\section{Results and Discussion}

\section{(a) Synthesis}

The compounds used in this study are shown in Scheme 1. The acyl compounds $\mathbf{1}$ and $\mathbf{2}$ and the corresponding alkyl derivatives $\mathbf{5}$ and $\mathbf{6}$ were synthesized according to the literature procedure, with minor modifications (see below). ${ }^{[19]}$ The new derivatives with $\mathrm{R}_{\mathrm{F}}=\mathrm{CH}_{2} \mathrm{CF}_{3}$ and $\mathrm{CF}_{2} \mathrm{CH}_{3}$ were obtained by a similar procedure, namely addition of in-situ generated $\left[\mathrm{Mn}(\mathrm{CO})_{5}\right]^{-}$to 3,3,3-trifluoropropanoyl chloride, $\mathrm{CF}_{3} \mathrm{CH}_{2} \mathrm{COCl}$, and 2,2-difluoropropanoyl chloride, $\mathrm{CH}_{3} \mathrm{CF}_{2} \mathrm{COCl}$, respectively, to yield the acyl derivatives 3 and $\mathbf{4}$, which were then decarbonylated to the alkyl derivatives 7 and 8. Both compounds with the $\mathrm{CH}_{2} \mathrm{CF}_{3}$ group ( 3 and 7) were isolated and fully characterized. The decarbonylation of 3 proceeded smoothly by heating at $70^{\circ} \mathrm{C}$ and the alkyl product 7 was recovered in acceptable yields. It is to be noted that the more direct reaction between $\left[\mathrm{Mn}(\mathrm{CO})_{5}\right]^{]}$and $\mathrm{CF}_{3} \mathrm{CH}_{2}$ I failed to produce 7, giving instead a complex mixture, in which [(CO) $\left.{ }_{5} \mathrm{Mnl}\right]$ was a major component. Quite clearly, the presence of three $F$ atoms on the $\beta-C$ atom is sufficient to invert the polarity of the $C-I$ bond. The decarbonylation of $\mathbf{4}$ was not successful under any of the employed conditions (different temperatures and with or without different solvents). The target product $\mathbf{8}$ was indeed formed, as indicated by the spectroscopic data (vide infra), but subsequently decomposed upon prolonged heating before completion of the acyl precursor decarbonylation. The best conditions found for this reaction are shown in the experimental section. The reason for this behavior is presumably the weaker homolytic $\mathrm{Mn}-\mathrm{C}$ bond strength in $\mathbf{8}$, as suggested by DFT calculations (see section on the homolytic bond strength determination below), ${ }^{[18]}$ resulting in a competition between the rate of thermal decarbonylation leading from $\mathbf{4}$ to $\mathbf{8}$ and the rate of product decomposition. For all other synthesized compounds, the purification steps were found more effective, faster and higher-yielding if carried out by column chromatography rather than by sublimation as in most of the previous reports. Another minor change relative to the literature procedures is the use of the $\mathrm{Na} / \mathrm{K}$ alloy to reduce $\left[\mathrm{Mn}_{2}(\mathrm{CO})_{10}\right]$, yielding $\left[\mathrm{Mn}(\mathrm{CO})_{5}\right]^{-}$as the potassium salt, ${ }^{[20]}$ rather than the more commonly employed sodium amalgam. ${ }^{[21]}$

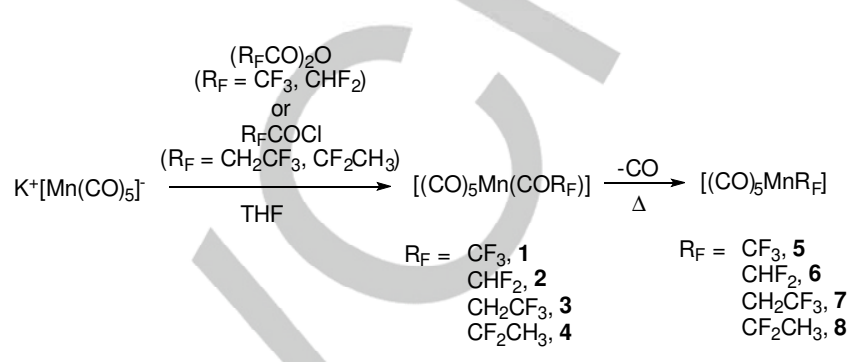

Scheme 1. Synthesis of pentacarbonylmanganese(I) compounds with fluoroalkyl groups.

Table 1. Selected ${ }^{1} \mathrm{H},{ }^{19} \mathrm{~F}$ and ${ }^{13} \mathrm{C}$ NMR chemical shifts $(\delta)$ in acetone- $d_{6}$, with coupling constants in parentheses (in Hertz), for $\left[(\mathrm{CO})_{5} \mathrm{Mn}\left(\mathrm{COR}_{\mathrm{F}}\right)\right]$ and $\left[(\mathrm{CO})_{5} \mathrm{Mn}\left(\mathrm{R}_{\mathrm{F}}\right)\right]$ compounds.

\begin{tabular}{|c|c|c|c|c|}
\hline $\mathrm{RF}_{\mathrm{F}}$ & ${ }^{1} \mathrm{H}$ & ${ }^{19} \mathrm{~F}$ & ${ }^{13} \mathrm{C}\left(\mathrm{C}^{\alpha}\right)$ & ${ }^{13} \mathrm{C}\left(\mathrm{C}^{\beta}\right)$ \\
\hline \multicolumn{5}{|c|}{ Acyl derivatives } \\
\hline 1 & - & $-81.9 \mathrm{~s}$ & $\begin{array}{c}115.0 q \\
\left({ }^{1} J_{C F}=302\right)\end{array}$ & - \\
\hline 2 & $\begin{array}{c}5.24 \mathrm{t}^{[\mathrm{a}]} \\
\left({ }^{2} J_{\mathrm{HF}}=57.8\right)\end{array}$ & $\begin{array}{c}-119.2 \mathrm{~d} \\
\left({ }^{2} J_{\mathrm{FH}}=57.8\right)\end{array}$ & $\begin{array}{c}111.5 \mathrm{dt} \\
\left({ }^{1} J_{\mathrm{CF}}=256,\right. \\
\left.{ }^{1} J_{\mathrm{CH}}=194\right)\end{array}$ & - \\
\hline 3 & $\begin{array}{c}4.05 q \\
\left({ }^{3} J_{H F}=10.8\right)\end{array}$ & $\begin{array}{c}-63.4 t \\
\left({ }^{3} J_{F H}=10.8\right)\end{array}$ & $\begin{array}{c}63.5 \mathrm{qt} \\
\left({ }^{2} J_{\mathrm{CF}}=22.6,\right. \\
\left.{ }^{1} J_{\mathrm{CH}}=131\right)\end{array}$ & $\begin{array}{c}123.3 \mathrm{tq} \\
\left({ }^{1} J_{\mathrm{CF}}=279\right. \\
\left.{ }^{2} J_{\mathrm{CH}}=6.7\right)\end{array}$ \\
\hline 4 & $\begin{array}{c}1.49 t \\
\left({ }^{3} J_{H F}=19.3\right)\end{array}$ & $\begin{array}{c}-91.5 \mathrm{q} \\
\left({ }^{3} J_{\mathrm{FH}}=19.4\right)\end{array}$ & $\begin{array}{c}117.9 \mathrm{tq} \\
\left({ }^{1} J_{\mathrm{CF}}=250,\right. \\
\left.{ }^{2} J_{\mathrm{CH}}=5.1\right)\end{array}$ & $\begin{array}{c}17.0 \mathrm{qt} \\
\left({ }^{2} J_{\mathrm{CF}}=26.1,\right. \\
\left.{ }^{1} J_{\mathrm{CH}}=129.5\right)\end{array}$ \\
\hline
\end{tabular}

Alkyl derivatives

5 $5.65 \mathrm{~s} \quad \begin{gathered}153.3 \mathrm{q} \\ \left({ }^{1} \mathrm{~J}_{\mathrm{CF}}=355\right)\end{gathered}$

6 $7.46 \mathrm{t}^{[\mathrm{b}]}$
$\left({ }^{2} \mathrm{~J}_{\mathrm{FH}}=48.6\right)$ $-71.6 \mathrm{~d}$ $\left({ }^{2} J_{\mathrm{FH}}=48.6\right)$ $143.8 \mathrm{dt}$ $\left({ }^{1} J_{\mathrm{CF}}=287\right.$, $\left.{ }^{1} \mathrm{~J}_{\mathrm{CH}}=175\right)$

\begin{tabular}{|c|c|c|c|c|}
\hline 7 & $\begin{array}{c}1.40 \mathrm{q} \\
\left({ }^{3} J_{\mathrm{HF}}=15.9\right)\end{array}$ & $\begin{array}{c}-52.3 t \\
\left({ }^{3} J_{\mathrm{FH}}=16.9\right)\end{array}$ & {$[c]$} & $\begin{array}{c}133.7 \mathrm{qt} \\
\left({ }^{1} J_{\mathrm{CF}}=273,\right. \\
\left.{ }^{2} J_{\mathrm{CH}}=6.0\right)\end{array}$ \\
\hline 8 & $\begin{array}{c}2.01 \mathrm{t}^{[\mathrm{d}]} \\
\left({ }^{3} J_{\mathrm{HF}}=24.0 \mathrm{~Hz}\right)\end{array}$ & $\begin{array}{c}-28.9 \\
\left({ }^{3} J_{F H}=23.9\right)\end{array}$ & [e] & [e] \\
\hline
\end{tabular}

[a] Cf. $4.85\left({ }^{2} \mathrm{~J}_{\mathrm{HF}}=59 \mathrm{~Hz}\right)$ in $\mathrm{CCl}_{4}{ }^{[6 \mathrm{aa}}[\mathrm{b}] \mathrm{Cf} .7 .23 \mathrm{t}\left({ }^{2} \mathrm{~J}_{\mathrm{HF}}=48.5\right)$ in $\mathrm{CCl}_{4}{ }^{[6 \mathrm{~b}]}[\mathrm{c}]$ Unidentified, perhaps overlapping with the strong solvent resonance. [d] Partially overlapping with the acetone- $d_{6}$ signal. Another NMR spectrum was carried out in benzene- $d_{6}$ to confirm the multiplicity of this peak (Figure S.A8.1). [e] Not available in sufficient amounts to record this spectrum. 


\section{(b) NMR characterization}

The ${ }^{1} \mathrm{H},{ }^{13} \mathrm{C}$ and ${ }^{19} \mathrm{~F}$ NMR spectra (shown in the SI, part A) reveal the expected chemical shifts and coupling patterns for all compounds, which are summarized in Table 1. The table also reports the full characterization of the derivatives with $\mathrm{R}_{\mathrm{F}}=\mathrm{CF}_{3}$ and $\mathrm{CHF}_{2}$. Curiously, although the latter are well-known compounds and have been analyzed by less routine techniques such as ${ }^{55} \mathrm{Mn} \mathrm{NMR}{ }^{[22]}$ and XPS, ${ }^{[23]}$ the more accessible properties shown in Table 1 have not all been previously reported to the best of our knowledge. The ${ }^{1} \mathrm{H}$ and ${ }^{19} \mathrm{~F}$ NMR spectra show that, as expected, the two-bond fluorine-proton coupling constants $\left({ }^{2} J_{\mathrm{HF}}\right)$ are greater than the three-bond constants $\left({ }^{3} J_{\mathrm{HF}}\right)$. The latter value increases on going from the $\mathrm{CH}_{2} \mathrm{CF}_{3}$ to the $\mathrm{CF}_{2} \mathrm{CH}_{3}$ species and from the acyl to the alkyl species. On the other hand, the ${ }^{2} J_{\mathrm{HF}}$ for the $\mathrm{CHF}_{2}$ derivatives is greater in the acyl one. In the ${ }^{19} \mathrm{~F}$ NMR spectra, the chemical shifts for the $\mathrm{CH}_{2} \mathrm{CF}_{3}$ acyl and alkyl compounds are rather similar, with only a slight downfield shift after decarbonylation, whereas all compounds with $\mathrm{F}$ substitution on the $\alpha-C$ atom undergo a much greater downfield shift, as a consequence of direct coordination of the alkyl group to the metal atom. The ${ }^{13} \mathrm{C}$ spectra show all the expected ${ }^{1} J_{\mathrm{CH}},{ }^{2} J_{\mathrm{CH}},{ }^{1} J_{\mathrm{CF}}$ and ${ }^{2} J_{\mathrm{CF}}$, with ${ }^{1} J_{\mathrm{CF}}>{ }^{1} J_{\mathrm{CH}}$ in compounds 2 and $\mathbf{6},{ }^{1} \mathrm{~J}_{\mathrm{CF}}>{ }^{2} J_{\mathrm{CF}}$ and ${ }^{1} J_{\mathrm{CH}}>$ ${ }^{2} J_{\mathrm{CH}}$. All these trends are as expected. The carbonyl region of the ${ }^{13} \mathrm{C}$ NMR spectra for compounds 1-4 (ca. $210 \mathrm{ppm}$ ) does not allow a clear distinction of the acyl carbonyl resonance, probably masked by the broad and stronger terminal $\mathrm{Mn}-\mathrm{CO}$ resonances.

\section{(c) X-ray diffraction studies}

As stated above, the $\mathrm{CF}_{3}$ and $\mathrm{CHF}_{2}$ acyl and alkyl systems have been known for quite some time but have not been structurally characterized in the crystalline state. Indeed, X-ray diffraction studies of $\left[(\mathrm{CO})_{5} \mathrm{Mn}(\mathrm{COR})\right]$ and $\left[(\mathrm{CO})_{5} \mathrm{MnR}\right]$ compounds are quite limited and do not include any example of fluorine-containing carbyl ligand bonded to $\mathrm{Mn}$ via an $\mathrm{sp}^{3}$-hybridized $\mathrm{C}$ atom. On the other hand, there are a few $\left[(\mathrm{CO})_{5} \mathrm{MnR}\right]$ structures with $\mathrm{F}$ containing groups bonded via an $\mathrm{sp}^{2}$-hybridized $\mathrm{C}$ atom. ${ }^{\left[{ }^{24]} \mathrm{We}\right.}$ have now determined the structures of the acyl compounds 1 and $\mathbf{2}$ and the corresponding alkyl compounds $\mathbf{5}$ and $\mathbf{6}$, as well as those of the new acyl derivative 4 and the new alkyl derivative 7 . Views of the three acyl derivatives 1, 2 and $\mathbf{4}$ are shown in Figure 1, while those of the alkyl derivatives 5, $\mathbf{6}$ and $\mathbf{7}$ are given in Figure 2. Selected bond distances and angles are collected in Table 2 and more extensive metric data are given in the SI (part B). Of particular interest are the $\mathrm{Mn}-\mathrm{C}$ distances to the $\mathrm{R}_{\mathrm{F}}$ groups for the three alkyl complexes 5, 6 and 7, because the homolytic bond strengths to these alkyl groups have been predicted to be greater than in the non-F-substituted analogues. ${ }^{[18]}$ For the structure of compound $\mathbf{6}$, the molecule sits on a crystallographic mirror plane that imposes a symmetry disorder between the $\mathrm{CHF}_{2}$ group and one of its cis CO ligands; a symmetry lowering did not provide a better crystallographic solution. Therefore, the parameters related to the two disordered groups are unreliable. In the better determined distance in $\mathbf{5}$, with three $\alpha-F$ substituents, the $\mathrm{Mn}_{-} \mathrm{CF}_{3}$ distance $(2.067(3) \AA)$ is ca. $0.1 \AA$ shorter than that to the $\mathrm{Mn}$ $\mathrm{CH}_{2} \mathrm{CF}_{3}$ distance in $7,2.162(2) \AA$. For comparison, other distances to $\mathrm{sp}^{3}$-hybridized $\mathrm{C}$ atoms without any $\mathrm{F}$ substituents are 2.214(3) $\AA$ in $\left[(\mathrm{CO})_{5} \mathrm{Mn}\left(\mathrm{CH}_{2} \mathrm{CH}=\mathrm{CHCOOPh}\right)\right]^{[25]}$ and 2.195(6) and 2.196(8) $\AA$ in $\left[(\mathrm{CO})_{5} \mathrm{Mn}\left(\mathrm{CH}_{2} \mathrm{CH}_{2}-\mathrm{O}-\mathrm{C}_{6} \mathrm{H}_{4}-\mathrm{CH}_{2} \mathrm{CH}_{2}\right) \mathrm{Mn}-\right.$ $(\mathrm{CO})_{5},{ }^{[26]}$ whereas positional disorder in the simpler reference compound $\left[(\mathrm{CO})_{5} \mathrm{Mn}\left(\mathrm{CH}_{3}\right)\right]$ prevented an accurate determination of the $\mathrm{Mn}-\mathrm{CH}_{3}$ distance. ${ }^{[27]}$ The distance in $\left[(\mathrm{CO})_{5} \mathrm{Mn}\left(\mathrm{CH}_{2} \mathrm{Cl}\right)\right]$, with one $\alpha$-Cl substituent, is $2.125(10) \AA_{.}^{[28]}$ These data suggest that electronegative substituents (particularly $\mathrm{F}$, but even $\mathrm{Cl}$ ), even when placed on the $\beta-C$ atom as in 7, strengthen the $\mathrm{Mn}-\mathrm{C}$ bond, in agreement with the recent DFT study. ${ }^{[18]}$

Table 2. Selected bond distances (in $\AA$ ) from the $X$-ray structures of $\left[(\mathrm{CO})_{5} \mathrm{Mn}\left(\mathrm{COR}_{\mathrm{F}}\right)\right]$ and $\left[(\mathrm{CO})_{5} \mathrm{Mn}\left(\mathrm{R}_{\mathrm{F}}\right)\right]$.

\begin{tabular}{|c|c|c|c|}
\hline Parameter & 1 & Acyl comp & 4 \\
\hline $\mathrm{Mn}-\mathrm{C}\left(\mathrm{COR}_{\mathrm{F}}\right)$ & $2.051(3)$ & $2.057(5)$ & $2.0748(14)$ \\
\hline $\mathrm{Mn}-\mathrm{CO}_{\text {trans }}$ & $1.869(3)$ & $1.869(6)$ & $1.8562(15)$ \\
\hline $\mathrm{Mn}-\mathrm{CO}_{\text {cis }}$ & $\begin{array}{l}1.872(3) \\
1.862(3) \\
1.863(3) \\
1.879(3)\end{array}$ & $\begin{array}{l}1.875(6) \\
1.880(6) \\
1.862(5) \\
1.858(6)\end{array}$ & $\begin{array}{l}1.8809(14) \\
1.8617(14) \\
1.8566(14) \\
1.8697(14)\end{array}$ \\
\hline Parameter & 5 & $\begin{array}{c}\text { Alkyl compo } \\
6\end{array}$ & $7^{\text {[a] }}$ \\
\hline $\mathrm{Mn}-\mathrm{C}\left(\mathrm{R}_{\mathrm{F}}\right)$ & $2.067(3)$ & $1.971(2)^{[b]}$ & $2.167(2) / 2.162(2)$ \\
\hline $\mathrm{Mn}-\mathrm{CO}_{\text {trans }}$ & $1.858(3)$ & $1.861(2)^{[b]}$ & $1.834(2) / 1.842(2)$ \\
\hline $\mathrm{Mn}-\mathrm{CO}_{\text {cis }}$ & $\begin{array}{l}1.872(2) \\
1.873(2)\end{array}$ & $\begin{array}{l}1.853(3) \\
1.859(3)\end{array}$ & $\begin{array}{l}1.871(2) / 1.870(2) \\
1.860(2) / 1.865(2) \\
1.869(2) / 1.868(2) \\
1.870(2) / 1.869(2)\end{array}$ \\
\hline
\end{tabular}

[a] Values for two independent molecules in the asymmetric unit. [b] Unreliable parameter because of symmetry-related disorder.

\section{(d) Infrared characterization}

The infrared analysis in the $\mathrm{Mn}-\mathrm{CO}$ stretching region has revealed unprecedented features. Table 3 collects the relevant data and also compares the measured frequencies with those already reported in the literature for the already known compounds (1, 2, 5 and 6). The spectra are shown in the SI (part C). Compound 8 could not be obtained in sufficiently pure form to record a reliable IR spectrum. The frequency trend indicates that the alkyl donor power varies in the increasing order $\mathrm{CF}_{3}<\mathrm{CHF}_{2}<\mathrm{CH}_{2} \mathrm{CF}_{3}$. The placement of the $\mathrm{CF}_{2} \mathrm{CH}_{3}$ derivative in this series is ambiguous because of the attenuated effect in the series of acyl derivatives (1-4). The $\mathrm{Mn}$-CO frequencies in the $\mathrm{COCF}_{2} \mathrm{CH}_{3}$ complex 4 appear rather similar to those in the $\mathrm{COCHF}_{2}$ complex 2. The presence of additional bands relative to the three ones $\left(2 A_{1}+E\right)$ expected for the $(\mathrm{CO})_{5} \mathrm{Mn}$ moiety in ideal $\mathrm{C}_{4 \mathrm{v}}$ symmetry is related to symmetry lowering, resulting in $E$ band splitting and in the appearance of the "forbidden" and therefore weak $B_{1}$ band. In addition, rotational isomerism results in the appearance of a second -COR vibration for the acyl derivatives. ${ }^{[6]}$ Additional weak bands are also observed in the Mn-CO stretching region (see Table 3). A few of these were also previously observed for the alkyl compounds 5 and $\mathbf{6}$ and attributed to ${ }^{13} \mathrm{C}$-containing isotopomers, ${ }^{[6 b]}$ but a detailed symmetry analysis has not been previously carried out. These bands cannot originate from byproducts that contain the fluoroalkyl groups because the compounds are spectroscopically pure $\left({ }^{1} \mathrm{H},{ }^{13} \mathrm{C},{ }^{19} \mathrm{~F} \mathrm{NMR}\right.$, SI part A). Their assignment to by-products that do not contain the fluoroalkyl group is also unlikely because the frequencies depend on the nature of this group. 

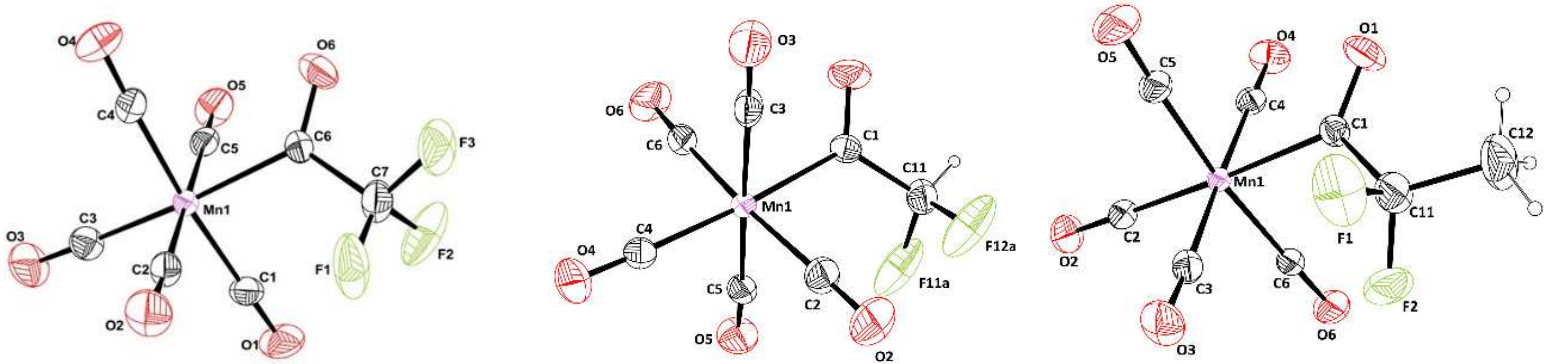

Figure 1. ORTEP views of the acyl compounds 1 (left), 2 (centre) and 4 (right). Thermal ellipsoids are drawn at the $50 \%$ level.
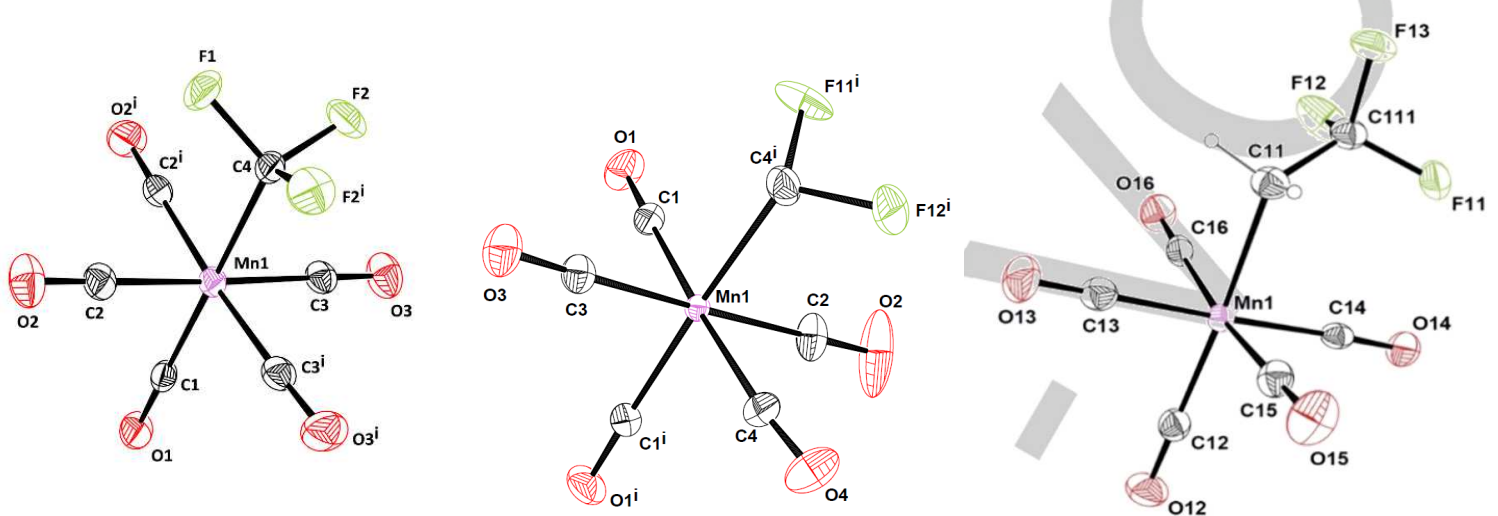

Figure 2. ORTEP views of the alkyl compounds $\mathbf{5}$ (left), $\mathbf{6}$ (center) and $\mathbf{7}$ (right). For the structure of $\mathbf{6}$, only one of the two symmetry-equivalent orientations of the $\mathrm{C} 1$ and $\mathrm{C} 4$ atoms is presented for clarity. Thermal ellipsoids are drawn at the $50 \%$ level.

Table 3. IR vibrations of $\left[(\mathrm{CO})_{5} \mathrm{Mn}(\mathrm{COR} F)\right]$ and $\left[(\mathrm{CO})_{5} \mathrm{Mn}\left(\mathrm{R}_{\mathrm{F}}\right)\right]$ compounds in the $\mathrm{CO}$ stretching region.

\begin{tabular}{|c|c|c|c|c|c|c|c|c|c|c|}
\hline $\mathrm{R}_{\mathrm{F}}$ & Solvent & & & & & & & & & Reference \\
\hline \multicolumn{2}{|c|}{ Acyl derivatives } & $A_{1}$ & $\mathrm{~B}_{1}$ & $E$ & $A_{1}$ & $\mathrm{~A}_{1}\left(\right.$ eq. $\left.{ }^{13} \mathrm{C}\right)$ & $\mathrm{E}_{(2)}\left(\right.$ eq. $\left.{ }^{13} \mathrm{C}\right)$ & $\mathrm{A}_{1}\left(\mathrm{ax} \cdot{ }^{13} \mathrm{C}\right)$ & acyl & \\
\hline 1 & pentane & $2131 w$ & $2070 w$ & 2039 vs & $2023 \mathrm{~s}$ & $2001 w$ & $1981 \mathrm{vw}$ & $1944 \mathrm{vw}$ & 1722 vw, 1665 w & This work ${ }^{[a]}$ \\
\hline \multirow[t]{2}{*}{2} & pentane & $2125 w$ & $2062 \mathrm{w}$ & 2036 s, 2028 s & $2015 \mathrm{~s}$ & - & - & - & $1658 w, 1643 w$ & [6a] \\
\hline & pentane & $2127 w$ & $2063 \mathrm{w}$ & 2038 vs, 2031 vs & $2017 \mathrm{~s}$ & $1997 \mathrm{w}$ & $1975 \mathrm{vw}$ & $1938 \mathrm{vw}$ & $1660 \mathrm{w}, 1645 \mathrm{w}$ & This work \\
\hline 3 & pentane & $2122 w$ & $2063 w$ & 2028 s, 2020 vs & $2012 \mathrm{~s}$ & $1975 \mathrm{vw}$ & - & $1940 \mathrm{vw}$ & $1663 w, 1652 w$ & This work \\
\hline 4 & pentane & $2125 w$ & 2061 w & 2037 vs, 2028 vs & $2014 \mathrm{~s}$ & 1994 w & 1972 vw & $1936 \mathrm{vw}$ & $1663 \mathrm{~m}, 1615 \mathrm{vw}$ & This work \\
\hline \multicolumn{2}{|c|}{ Alkyl derivatives } & $A_{1}$ & $\mathrm{~B}_{1}$ & E & $A_{1}$ & & $\mathrm{E}(2)\left(\right.$ eq. $\left.{ }^{13} \mathrm{C}\right)$ & $\mathrm{A} 1\left(\mathrm{ax} .{ }^{13} \mathrm{C}\right)$ & & \\
\hline \multirow[t]{3}{*}{5} & pentane & $2137 \mathrm{w}^{[\mathrm{b}]}$ & $2075 \mathrm{vw}^{[\mathrm{cc}]}$ & 2045 vs & $2021 \mathrm{~s}$ & $2010 w$ & $1978 \mathrm{vw}$ & $1940 \mathrm{vw}$ & - & This work \\
\hline & heptane & $2136 w$ & 2068 sh & 2044 vs & $2019 \mathrm{~s}$ & $2007 w$ & 1977 vw & - & - & [6b] \\
\hline & cyclohexane & 2134.5 & $(2072)^{[d]}$ & 2043.4 & 2019.5 & - & - & - & - & [29] \\
\hline \multirow[t]{2}{*}{6} & pentane & $2128 w$ & $2064 w$ & 2031 vs & $2011 \mathrm{~s}$ & $1984 \mathrm{sh}$ & $1970 \mathrm{vw}$ & $1930 \mathrm{vw}$ & - & This work \\
\hline & heptane & $2127 w$ & $\begin{array}{l}2062 \mathrm{w} \\
2044 \mathrm{sh}\end{array}$ & 2029 vs & $2010 \mathrm{~s}$ & $1982 w$ & $1968 \mathrm{vw}$ & - & - & [6b] \\
\hline 7 & pentane & $2124 w$ & $2062 \mathrm{w}$ & 2030 vs & $2004 \mathrm{~s}$ & ca. 1990 sh & $1962 \mathrm{vw}$ & $1930 \mathrm{vw}$ & - & This work \\
\hline
\end{tabular}

[a] Cf. $2139 \mathrm{w}-\mathrm{m}, 2035 \mathrm{vs}, 2002 \mathrm{~m}(\mathrm{sh}), 1643 \mathrm{~m}-\mathrm{s}$ in KBr pellet. ${ }^{[4]}[\mathrm{b}]$ Shoulder (vw) at 2127 assigned to the $\mathrm{A}_{1}$ band of the eq- ${ }^{13} \mathrm{C}$ isotopomer. [c] A second weak band at $2066 \mathrm{~cm}^{-1}$ is assigned to the $B_{1}$ vibration of the eq ${ }^{-13} \mathrm{C}$ isotopomer, see text and Figure 4. [d] Value obtained from the Raman spectrum. 


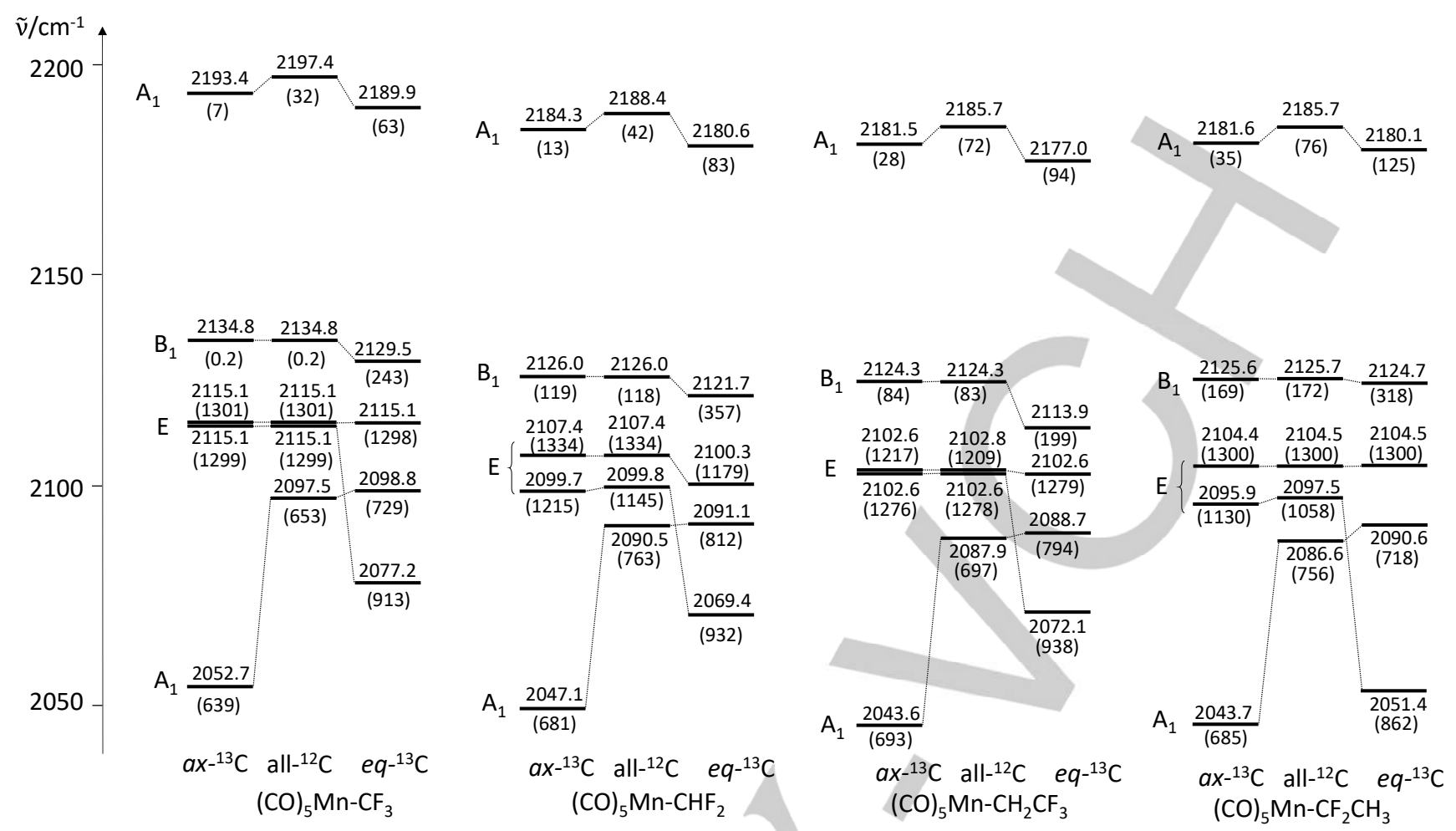

Figure 3: DFT-calculated terminal Mn-CO stretching frequencies $\left(\right.$ in $\left.\mathrm{cm}^{-1}\right)$ and relative intensities (in parentheses) for the $(C O)_{5} M n R_{F}$ complexes $5\left(R_{F}=C F_{3}\right), 6\left(R_{F}\right.$ $\left.=\mathrm{CHF}_{2}\right), 7\left(\mathrm{R}_{\mathrm{F}}=\mathrm{CH}_{2} \mathrm{CF}_{3}\right)$ and $8\left(\mathrm{R}_{\mathrm{F}}=\mathrm{CF}_{2} \mathrm{CH}_{3}\right)$.

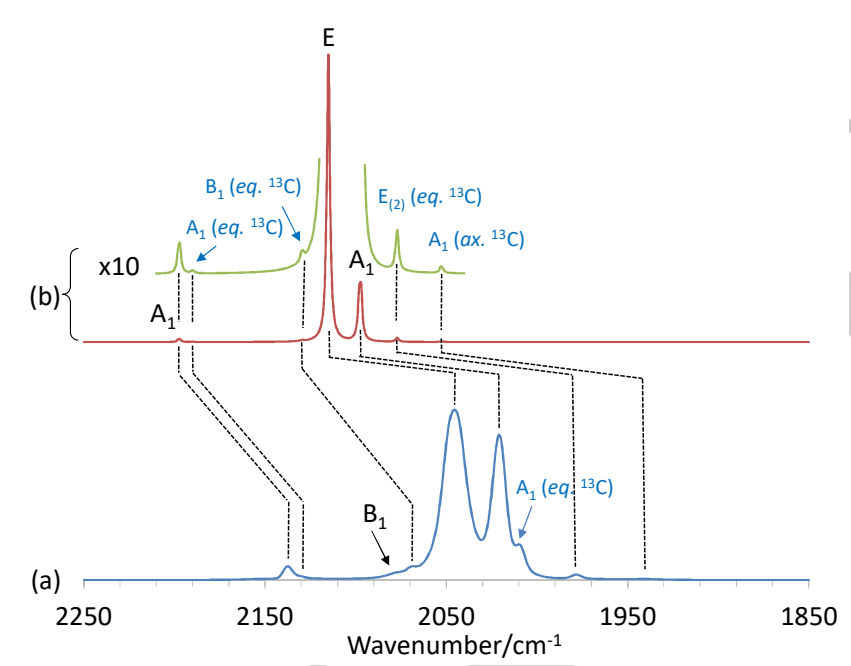

Figure 4. Experimental (a) and DFT-calculated (b) IR spectra of compound 5 in the terminal carbonyl stretching region. For the calculated spectrum, the bands are reported as Lorentzian functions with $2 \mathrm{~cm}^{-1}$ half-height width and relative intensities as indicated by the calculations. The spectra of the $\left[\left({ }^{12} \mathrm{CO}\right)_{5} \mathrm{Mn}\left(\mathrm{CF}_{3}\right)\right]$, $\left[\left(e q^{-13} \mathrm{CO}\right)\left({ }^{12} \mathrm{CO}\right){ }_{4} \mathrm{Mn}\left(\mathrm{CF}_{3}\right)\right]$ and $\left[\left(a x^{-13} \mathrm{CO}\right)\left({ }^{12} \mathrm{CO}\right)_{4} \mathrm{Mn}\left(\mathrm{CF}_{3}\right)\right]$ isotopomers were summed up with relative contributions calculated from the ${ }^{13} \mathrm{C}$ natural abundance and the isotopomers with double (or more) ${ }^{13} \mathrm{C}$ substitution were neglected.

A full frequency analysis was carried out by DFT calculations for all alkyl complexes (5-8). A summary of the calculated frequencies is shown in Figure 3 and a comparison of the DFTcalculated and the experimental IR spectrum for the representative compound $\mathbf{5}$ is illustrated in Figure 4. Analogous comparisons for compounds 6 and 7 are reported in the SI (part D). The calculated spectrum is shifted to higher wavenumbers relative to the experimental one, which is a common phenomenon for DFT-calculated IR spectra, but the general shape of the spectrum is reproduced quite well. The calculations confirm the relative order of alkyl donor power established from the experimental spectra (see above) and allow assessing the donor power of the $\mathrm{CF}_{2} \mathrm{CH}_{3}$ substituent in $\mathbf{8}$ as being relatively similar to that of the $\mathrm{CH}_{2} \mathrm{CF}_{3}$ substituent in 7 (the frequency changes are small and of opposite sign for bands of different symmetry type). The calculations not only confirm the previous assignment of the main (all- ${ }^{12} \mathrm{C}$ ) isotopomer bands for compounds 5 and $6,{ }^{[6,29]}$ but also allowed clear identification and assignment of a few weak bands related to the ${ }^{13} \mathrm{C}$-containing isotopomers.

Three weak bands are visible on the low frequency side of the last band $\left(A_{1}\right)$ of the main isotopomer. One results from the significant shift of one of the two E-type bands for the isomer with equatorial ${ }^{13} \mathrm{C}$. A second one (not previously reported) is the lower-energy $\mathrm{A}_{1}$ band for the isotopomer with axial ${ }^{13} \mathrm{C}$. The assignment of the last one of these three bands, which is clearly visible at $2010 \mathrm{~cm}^{-}$ 1 for 5 (see Figure 4) but only as a shoulder of the stronger $A_{1}$ band for 6 and 7 (Figures S.D.1 and S.S.2), is less straightforward. On the basis of our DFT analysis (Figure 3 ), the only band that could appear in this region is the eq- ${ }^{13} \mathrm{C}$ isotopomer lowerfrequency $A_{1}$ vibration and we therefore tentatively assign it to this vibrational mode. However, the calculations predict a blue-shift upon isotopic substitution. This outcome may originate from an altered mixing of the $\mathrm{Mn}-\mathrm{CO}$ vibrators in the two $\mathrm{A}_{1}$ normal modes, whereas the mere isotopic substitution should lead to a red-shift. 
Possibly, the actual situation in $n$-pentane solution is different than in the gas phase and indeed results in the expected red-shift. A shoulder on the low-frequency side of the high-frequency $A_{1}$ band, which is visible for all three compounds, seems attributable to the corresponding $A_{1}$ vibration of the eq- ${ }^{13} \mathrm{C}$ isotopomer. The weak band at $2066 \mathrm{~cm}^{-1}$ for compound $\mathbf{5}$, slightly blue-shifted from the strongest $\mathrm{E}$ band of the main isotopomer, is assigned to the eq ${ }^{13} \mathrm{C}$ isotopomer $\mathrm{B}_{1}$ mode. This band gains in intensity relative to the corresponding one of the main isotopomer (243 relative to 0.2 , see Figure 3) because the vibrator local $\mathrm{C}_{4 \mathrm{v}}$ symmetry is broken by the isotopic substitution. The weaker and further blueshifted band in the experimental spectrum (shoulder at ca. 2080 $\mathrm{cm}^{-1}$ ) is tentatively attributed to the $B_{1}$ vibration, possibly gaining intensity relative to the gas-phase calculated spectrum by dynamic symmetry breaking resulting from solvation. For the other two alkyl derivatives $\mathbf{6}$ and $\mathbf{7}$, the lower symmetry of the alkyl group renders the $B_{1}$ band more intense and clearly visible, as shown in both the experimental and calculated spectra (see SI), while that of the $e q^{-13} \mathrm{C}$ isotopomer is hidden underneath the stronger $B_{1}$ and $E$ bands of the main isotopomer. All other calculated bands of the $e q-{ }^{13} \mathrm{C}$ and $a x-{ }^{13} \mathrm{C}$ isotopomers overlap with the stronger bands of the main all- ${ }^{-12} \mathrm{C}$ component.

\section{(e) Determination of the activation barrier for the homolytic Mn- $\mathbf{R}_{\mathrm{F}}$ bond cleavage}

This study was only carried out for compounds 5, 6 and 7, because compound $\mathbf{8}$ could not be obtained in sufficient quantities and in a sufficiently pure state. Under thermal activation at constant temperature, the residual $\left[(\mathrm{CO})_{5} \mathrm{Mn}\left(\mathrm{R}_{\mathrm{F}}\right)\right]$ concentration was monitored by ${ }^{19} \mathrm{~F}$ NMR spectroscopy in the presence of hexafluorobenzene as internal standard plus a large amount of a radical trapping agent ( $T$, see Scheme 2 ), sufficient to insure saturation kinetics (reaction rate limited by the bond cleavage step and a first order decay, $\left.-\mathrm{d}\left[(\mathrm{CO})_{5} \mathrm{Mn}\left(\mathrm{R}_{\mathrm{F}}\right)\right] / \mathrm{dt}=k_{\mathrm{a}}\left[(\mathrm{CO})_{5} \mathrm{Mn}\left(\mathrm{R}_{\mathrm{F}}\right)\right]\right)$. The same protocol was previously employed for the measurement of activation barriers for other radical-generating reactions, for instance the homolytic splitting of metal-metal bonds, ${ }^{[30]}$ the Co ${ }^{\text {III- }} \mathrm{R}$ cleavage in vitamin $\mathrm{B} 12^{[31]}$ and related model compounds, ${ }^{[32]}$ or the alkyl halide activation by metal catalysts in atom transfer radical polymerization systems. ${ }^{[33]}$ For the metalmetal and metal-carbon breaking processes, where the reverse reaction is presumed to have a very small activation barrier, the kinetic activation enthalpy was considered as a good upper-limit approximation of the thermodynamic bond dissociation enthalpy (BDE). An important difference between the present system and the above-cited precedents is that the co-product of the organic radical (equation 1), namely $\left[(\mathrm{CO})_{5} \mathrm{Mn}^{\circ}\right]$, is itself a reactive radical. In addition to efficiently trapping the $R_{F}{ }^{*}$ radical in equation 2 $\left(k_{\text {trap, } \mathrm{R}}[\mathrm{T}]>k_{\mathrm{da}}\left[(\mathrm{CO})_{5} \mathrm{Mn} \cdot\right]\right)$, the trapping agent $\mathrm{T}$ may also possess the ability to efficiently trap the $\left[(\mathrm{CO})_{5} \mathrm{Mn}^{\circ}\right]$ radical (equation 3a) $\left(k_{\text {trap, Mn }}[T]>>k_{d a}\left[R_{F^{*}}\right]\right)$. It is also known from flash photolysis studies that the bimolecular coupling of the $\left[(\mathrm{CO})_{5} \mathrm{Mn}{ }^{*}\right]$ radicals (equation $3 \mathrm{~b})$ is an extremely fast process $\left(k_{\text {dim }}=1.9 \cdot 10^{9}\right.$ $\left.\mathrm{M}^{-1} \mathrm{~S}^{-1}\right) \cdot{ }^{[34]}$ It has to be mentioned here that the BDE of the Mn-C bond in compounds 5 and $\mathbf{6}$ has also been indirectly estimated by Calvet calorimetry ${ }^{[35]}$ and by photoionization mass spectrometry. ${ }^{[36]}$

The selection of an appropriate trapping agent is of key importance. A successful trapping agent must not only react rapidly and irreversibly with $R_{F}$ (and possibly also with $\left.\left[(\mathrm{CO})_{5} \mathrm{Mn}^{\circ}\right]\right)$; it must also be inert relative to the starting compound $\left[(\mathrm{CO})_{5} \mathrm{Mn}\left(\mathrm{R}_{\mathrm{F}}\right)\right]$ under the thermal degradation conditions. We initially considered TEMPO, since this compound was used in several of the above-mentioned radical trapping studies. However, preliminary experiments carried out on compound 7 did not lead to the formation of the expected TEMPO- $\mathrm{CH}_{2} \mathrm{CF}_{3}$ product $\left({ }^{19} \mathrm{~F}\right.$ NMR signal reported at $\delta-71.58$ in $\left.\mathrm{CDCl}_{3}\right)^{[37]}$ and did not reveal the expected simple kinetic behavior (details in the SI, part E.1). A potential problem is the action of TEMPO as a ligand. ${ }^{[38]}$ Coordination to $\mathrm{Mn}^{\prime}$ may occur at a site left vacant by $\mathrm{CO}$ dissociation or by migratory insertion, followed by degradation by a pathway that does not involve $\mathrm{Mn}-\mathrm{C}$ bond cleavage as the initial step. Our attention was therefore turned toward tris(trimethylsilyl)silane, (TMS) ${ }_{3} \mathrm{SiH}$ (TTMSS), since this molecule can be reasonably expected to display poorer coordinating properties than TEMPO. It has been extensively used as a radical-based reducing agent ${ }^{[39]}$ and as an efficient $\mathrm{H}$ atom donor to a variety of carbon-centered radicals $\mathrm{R}^{\cdot} \cdot{ }^{[40]}$ It has also been shown that the $\left(\mathrm{Me}_{3} \mathrm{Si}_{3} \mathrm{Si}^{\circ}\right.$ radical generated by $\mathrm{H}$ atom transfer dimerizes to $\mathrm{Si}_{2}\left(\mathrm{SiMe}_{3}\right)_{6} \cdot{ }^{[41]}$ Furthermore, $\mathrm{Si}_{2}\left(\mathrm{SiMe}_{3}\right)_{6}$ is known to react with $\left[\mathrm{Mn}_{2}(\mathrm{CO})_{10}\right]$ to produce $\left[(\mathrm{CO})_{5} \mathrm{MnSi}\left(\mathrm{SiMe}_{3}\right)_{3}\right]$ with liberation of $\mathrm{H}_{2}{ }^{\left[{ }^{42]}\right.}$ The use of the related $\mathrm{Me}_{3} \mathrm{SiH}$ to trap $\mathrm{CH}_{3}$ radicals thermally generated from $\left[\mathrm{Mn}(\mathrm{CO})_{5}\left(\mathrm{CH}_{3}\right)\right]$ has previously been described, although that investigation did not assess the barrier to the homolytic bond cleavage. ${ }^{[43]}$

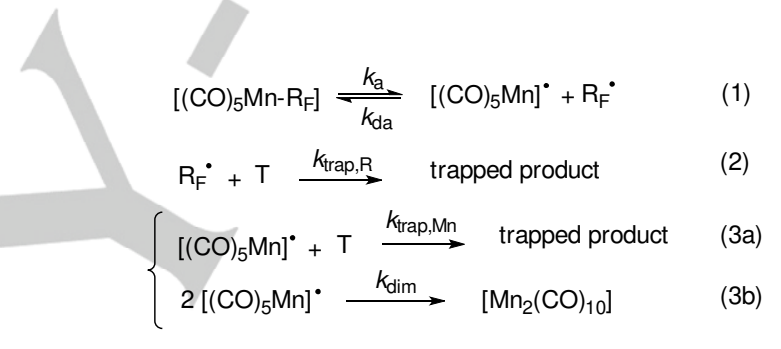

Scheme 2. Thermal decomposition of (fluoro)alkylpentacarbonylmanganese(I) compounds in presence of a radical trap.

Table 4. Kinetics and activation parameters for the decay of compounds 5,6 and 7 in $\mathrm{C}_{6} \mathrm{D}_{6}$.

\begin{tabular}{|c|c|c|c|c|c|c|}
\hline & \multirow{2}{*}{$\mathrm{T} /{ }^{\circ} \mathrm{C}$} & \multirow{2}{*}{$k_{a} / s^{-1}$} & \multicolumn{2}{|c|}{$\Delta H^{\ddagger} / \mathrm{kcal} \mathrm{mol}^{-1}$} & \multicolumn{2}{|c|}{$\Delta S^{\ddagger} / \mathrm{cal} \mathrm{mol}^{-1} \mathrm{~K}^{-1}$} \\
\hline & & & Exp. & DFT [a] & Exp. & $\mathrm{DFT}^{[\mathrm{a}]}$ \\
\hline \multirow{3}{*}{5} & 100 & $(3.10 \pm 0.18) \cdot 10^{-4}$ & & & & \\
\hline & 95 & $(1.04 \pm 0.06) \cdot 10^{-4}$ & $(53.8 \pm 3.5)^{[b]}$ & 55.1 & $(66.0 \pm 9.5)$ & 45.8 \\
\hline & 90 & $(4.08 \pm 0.29) \cdot 10^{-5}$ & & & & \\
\hline \multirow{3}{*}{6} & 85 & $(6.27 \pm 0.33) \cdot 10^{-4}$ & & & & \\
\hline & 80 & $(2.51 \pm 0.08) \cdot 10^{-4}$ & $(46.3 \pm 1.6)^{[c]}$ & 48.0 & $(55.8 \pm 4.7)$ & 43.2 \\
\hline & 75 & $(9.40 \pm 0.13) \cdot 10^{-5}$ & & & & \\
\hline \multirow{3}{*}{7} & 90 & $(5.35 \pm 0.07) \cdot 10^{-4}$ & & & & \\
\hline & 80 & $(7.84 \pm 0.47) \cdot 10^{-5}$ & $(50.6 \pm 0.8)$ & 50.5 & $(65.4 \pm 2.2)$ & 48.8 \\
\hline & 70 & $(8.52 \pm 0.41) \cdot 10^{-6}$ & & & & \\
\hline
\end{tabular}

[a] Values from ref. ${ }^{[18]}$. [b] Reported as $48.5 \pm 1.4 \mathrm{kcal} / \mathrm{mol}$ by Calvet calorimetry ${ }^{[35]}$ after re-evaluation, ${ }^{[36]}$ and as $43.5 \pm 2.6 \mathrm{kcal} / \mathrm{mol}$ by photoionization mass spectrometry. ${ }^{[36]}$ [c] Reported as $34.4 \pm 2.6 \mathrm{kcal} / \mathrm{mol}$ by photoionization mass spectrometry. ${ }^{[36]}$ 
Initial experiments, carried out on compound 5 at $100{ }^{\circ} \mathrm{C}$ in $\mathrm{C}_{6} \mathrm{D}_{6}$ as solvent with variable [TTMSS]/[Mn] ratio, revealed that a 10fold excess of the silane is sufficient to insure saturation conditions ([TTMSS]-independent observed pseudo-first order rate constant), see SI (part E2) for details. The ${ }^{19} \mathrm{~F}$ NMR monitoring allowed to derive the manganese complex decomposition kinetics (Figure S.E2.2) and gave unambiguous evidence for the production of $\mathrm{CHF}_{3}$ (Figure S.E2.3), although detection of this product was made difficult by its extensive escape toward the tube head space (b.p. $=-82.1^{\circ} \mathrm{C}$, low solubility in $\mathrm{C}_{6} \mathrm{D}_{6}$ ). Hence, all subsequent experiments were carried out with a 10-fold excess of TTMSS, see results in Table 4. All the first order decay plots are available in the SI (part E3). The Eyring analysis of the decay rate constants (Figure 5) provided the activation parameters that are also reported in Table 4. Note that the activation enthalpies obtained from the present study are greater than the thermodynamic bond dissociation enthalpies (BDEs) determined by Calvet calorimetry or by photoionization mass spectrometry, ${ }^{[35-36]}$ see footnotes in Table 4. This discrepancy might result from an overestimation of the BDEs by the kinetic approach but, as argued above, the reverse bond formation process should proceed via a very low activation barrier thus $\Delta H^{+} \approx$ BDE. The BDEs estimated by recent DFT calculations ${ }^{[18]}$ are in much closer agreement with the $\Delta H^{\ddagger}$ values determined by the present study. It is also worth underlining that the activation entropies obtained from the Eyring analyses of the rate data are high and positive, also in relatively good agreement with the values obtained by DFT calculation for the full bond breaking process. Note that other calculations of the Mn-C bond strength for compounds $\mathbf{5}$ and $\mathbf{6}$, carried out at a slightly different level of theory by Folga and Ziegler, ${ }^{[44]}$ also gave high values in close agreement with those of the more recent DFT study and these authors concluded that the experimental estimates of the $\mathrm{Mn}-\mathrm{C}$ BDEs available at that time were too low.

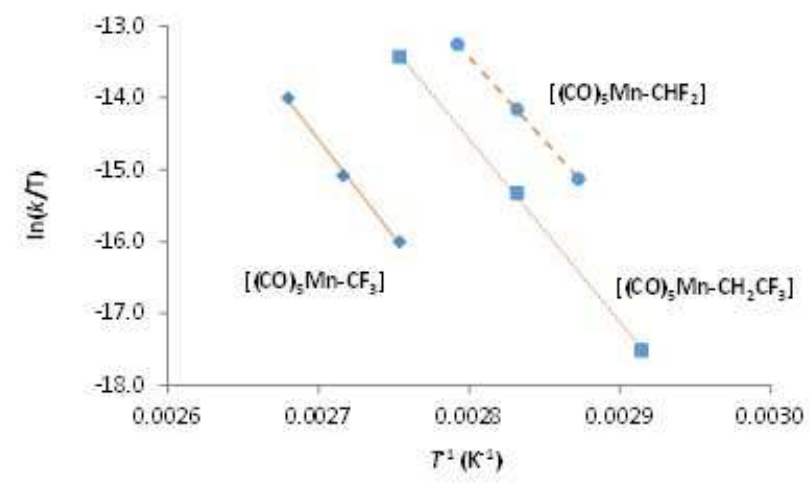

Figure 5. Eyring plots of $k_{\mathrm{obs}}$ as a function of temperature for the decomposition of compounds 5,6 and 7 .

In view of the forcing conditions used for this study, it is reasonable to question the existence of competing processes. Indeed, alkylpentacarbonylmanganese $(\mathrm{I})$ derivatives are known to be prone to thermally activated migratory insertion and decarbonylation processes. These would generate vacant coordination sites opening access to other reaction pathways such as $\alpha$ - and $\beta$-elimination processes of atoms $(H, F)$ from the alkyl chain. However, compounds 5-7 were found thermally stable in the absence of TTMSS. The interactions of silane with the reaction intermediates generated by migratory insertion and by decarbonylation have been investigated in silico, confirming that the homolytic cleavage pathway is the preferred one. These results will be reported separately in a forthcoming contribution. Finally, we point out that the calculated BDE for compound 8 (46.0 $\left.\mathrm{kcal} \mathrm{mol}^{-1}\right),{ }^{[18]}$ is slightly lower than those of the other three compounds, possibly rationalizing the failure to obtain this product by clean decarbonylation of $\mathbf{4}$ as suggested above in section (a).

\section{(f) VDF polymerization with compound 5}

Preliminary investigations of the radical generation from these fluoroalkyl derivatives of pentacarbonylmanganese $(\mathrm{I})$ were carried out using compound $\mathbf{5}$, which is the member of the series with the homolytically strongest bond according to both the experimental and the computational evidence, as an initiator for the polymerization of VDF. Full investigations of these complexes as radical polymerization initiators will be reported separately in a specialized polymer journal. The experiments were carried out in dimethyl carbonate under different conditions, see Table 5: thermal activation (entries 1 and 2), visible light at $40^{\circ} \mathrm{C}$ (entry 3 ) and UV $(300 \mathrm{~nm})$ irradiation at $50^{\circ} \mathrm{C}$ (entry 4$)$, using a molar ratio $[\mathrm{VDF}] /[5]=50$.

Table 5. Yields, molar masses and dispersities (obtained by SEC using PMMA standards) of PVDF prepared by the radical polymerization of VDF initiated by compound 5 . $^{[a]}$

\begin{tabular}{llllll} 
Entry & Activ. method & $\mathrm{T}\left({ }^{\circ} \mathrm{C}\right)$ & Yield $(\%)$ & $M_{\mathrm{n}}\left(\mathrm{g} \cdot \mathrm{mol}^{-1}\right)$ & $Ð$ \\
\hline 1 & Thermal & 50 & 0 & - & - \\
2 & Thermal & 100 & 68 & 16,900 & 1.53 \\
3 & Visible light & 40 & 60 & 40,300 & 1.47 \\
4 & UV light & 50 & 74 & 24,800 & 1.54 \\
\hline
\end{tabular}

[a] $\approx 1.5 \mathrm{~g}$ of VDF in $5 \mathrm{~mL}$ of dimethyl carbonate solution, $V_{\text {tot }} \approx 12 \mathrm{~mL}$, $24 \mathrm{~h}$.

Indeed, these processes led to the formation of polymer in high yields $(\geq 60 \%)$ after $24 \mathrm{~h}$, except when the thermal activation was carried out at $50^{\circ} \mathrm{C}$ without irradiation (entry 1 ). After precipitation, the recovered product was proven to correspond to PVDF by ${ }^{1} \mathrm{H}$ and ${ }^{19} \mathrm{~F}$ NMR spectroscopic analyses (SI, part F). The NMR solutions were clear, indicating the absence of inorganic metal impurities. The ${ }^{1} \mathrm{H}$ NMR spectra (Figures S.F.1, S.F.3 and S.F.5 for the products of thermal, visible and UV activation experiments) confirm the presence of both normal head-to-tail (HT) and inverted tail-to-tail (TT) dyads with characteristic signals located at 2.8-3.2 and 2.4 ppm, respectively. ${ }^{[12 a, 13 c, 45]}$ Chain-end signals, assigned to PVDF-CF $-\mathrm{CH}_{3}$ and PVDF- $\mathrm{CH}_{2}-\mathrm{CF}_{2} \mathrm{H}$, respectively, are also observed at 1.9 and 6.3 ppm. ${ }^{[45-46]}$ These signals result from chain transfer by the strong head and tail radicals to the solvent or monomer or from backbiting. ${ }^{[46 a]}$ The corresponding ${ }^{19} \mathrm{~F}$ NMR spectra (Figures S.F.2, S.F.4 and S.F.6) display a major signal centered at $-92 \mathrm{ppm}$ for the regular head-to-tail dyads and lower intensity signals at -114.6 and $-117.0 \mathrm{ppm}$, resulting from the $\mathrm{HH}$ addition, and a doublet of multiplets centered at -115.5 
ppm assigned to $\mathrm{CF}_{2} \mathrm{H}$ end-group in PVDF- $\mathrm{CH}_{2}-\mathrm{CF}_{2} \mathrm{H}^{\left[{ }^{[12 a,}, 13 \mathrm{c}, 45\right]}$ In addition, small signals centered at -115.1 and $-116.6 \mathrm{ppm}$ might be attributed to the $\beta$ and $y \mathrm{CF}_{2}$ groups relative to the manganese atom in PVDF- $\mathrm{CH}_{2} \mathrm{CF}_{2}-\mathrm{CF}_{2} \mathrm{CH}_{2}-\mathrm{Mn}(\mathrm{CO})_{5}$, respectively.

The SEC analysis (Figure 6 ) reveals monomodal and relatively narrow MW distributions, which can be considered relatively narrow because a PVDF made under similar conditions $\left(73^{\circ} \mathrm{C}\right.$ in dimethyl carbonate) by free radical polymerization showed, as expected, a dispersity value $(\Theta)$ of 2.1 . The highest molar mass product was obtained from the visible light activation experiment and the lowest one from the thermal activation experiment. These molar masses are overestimated because of the use of PMMA standards. However, the dispersities are similar for all products. The negative signal in the size exclusion chromatogram results from the lower refractive index of PVDF relative to the DMF eluent. ${ }^{[46 b-d]}$

Control experiments carried out with $\left[\mathrm{Mn}_{2}(\mathrm{CO})_{10}\right]$ instead of complex 5 did not yield any PVDF. Since $\left[\mathrm{Mn}_{2}(\mathrm{CO})_{10}\right]$ is known to generate $\left[(\mathrm{CO})_{5} \mathrm{Mn}^{\circ}\right]$ under both thermal and photochemical conditions, it can be concluded that the free $\left[(\mathrm{CO})_{5} \mathrm{Mn}^{\circ}\right]$ radicals are not capable to add onto VDF to initiate the polymerization. These results confirm previous studies by Bamford et al. ${ }^{[47]}$ and by Asandei et al., ${ }^{[12 a]}$ where $\left[(\mathrm{CO})_{5} \mathrm{Mn}^{*}\right]$ photoproduced from $\left[\mathrm{Mn}_{2}(\mathrm{CO})_{10}\right]$ was shown unable to initiate the radical polymerization of VDF (although it does initiate those of $\mathrm{C}_{2} \mathrm{~F}_{4}$ and $\mathrm{C}_{2} \mathrm{~F}_{3} \mathrm{Cl}$ ).

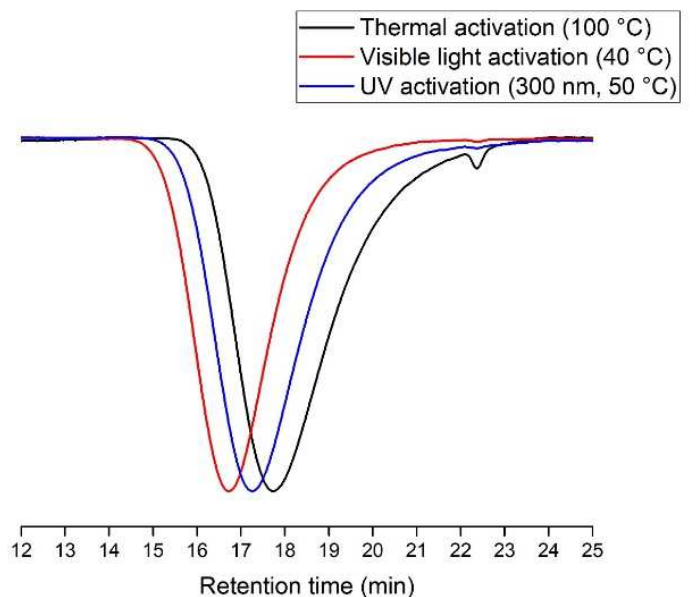

Figure 6. SEC traces of PVDF (entries 2, 3 and 4 in Table 5) in DMF.

Since VDF is known to polymerize only by the radical mechanism, the above results constitute proof of the generation of radicals by thermal decomposition of $\mathbf{5}$. The major primary radical generated by this process, as shown above, is $\mathrm{CF}_{3}$. This radical is known to selectively add to the tail end of VDF to generate the $\mathrm{CF}_{3} \mathrm{CH}_{2} \mathrm{CF}_{2}$ end group, for which the $\mathrm{CF}_{3}{ }^{19} \mathrm{~F} \mathrm{NMR}$ signal is expected at -60.1 ppm. ${ }^{[48]}$ However, the identification of this chain end was prevented by the high molar mass of the recovered polymer, except for entry 3 where a very small signal at $-61.4 \mathrm{ppm}$ could be observed (Figure S.F.6.2), although not strong enough for integration. The high molar masses relative to the calculated values for an ideal controlled process show low initiator efficiencies (with apparent values calculated from the molar masses estimated by SEC equal to $0.19,0.08$ and 0.13 for the thermal, visible and UV methods, respectively), indicating that the thermal activation method is the most efficient one. Since the kinetic studies of the thermal decomposition (section b), backed up by the DFT calculations, clearly show that $\mathbf{5}$ has the strongest $\mathrm{Mn}-\mathrm{R}_{\mathrm{F}} \mathrm{BDE}$ amongst all investigated compounds, there is little doubt that the other compounds (6-8) would also be able to function as radical initiators.

\section{Conclusions}

The new fluoroalkyl derivatives of pentacarbonylmanganese(I), $\left[\mathrm{Mn}(\mathrm{CO})_{5}\left(\mathrm{R}_{\mathrm{F}}\right)\right]\left(\mathrm{R}_{\mathrm{F}}=\mathrm{CH}_{2} \mathrm{CF}_{3}, 7 ; \mathrm{CF}_{2} \mathrm{CH}_{3}, 8\right)$, which are models of the "head" and "tail" dormant chains of PVDF resulting from the radical chain trapping by the $\left[(\mathrm{CO})_{5} \mathrm{Mn}^{*}\right]$ radical, have been prepared and investigated. Compound 8 could not be obtained in a pure state, presumably because the homolytic $\mathrm{Mn}-\mathrm{CF}_{2} \mathrm{CH}_{3}$ bond dissociation occurs simultaneously with its generation under the harsh thermal conditions of the acyl precursor decarbonylation. The spectroscopic characterization of compounds $1-8$ by ${ }^{1} \mathrm{H},{ }^{13} \mathrm{C}$ and ${ }^{19} \mathrm{~F}$ NMR provides useful and previously unavailable reference values for fluoroalkyl groups bonded to $\mathrm{Mn}(\mathrm{CO})_{5}$. In addition, the IR properties of the alkyl complexes 5-7 in solution have been fully explored at un unprecedented level of detail with the assistance of DFT calculations, resulting in the full symmetry analysis of the major $\left[\mathrm{Mn}\left({ }^{12} \mathrm{CO}\right)_{5}\left(\mathrm{R}_{\mathrm{F}}\right)\right]$ and minor $\left[\mathrm{Mn}\left({ }^{12} \mathrm{CO}\right)_{4}\left(e q-{ }^{13} \mathrm{CO}\right)\left(\mathrm{R}_{\mathrm{F}}\right)\right]$ and $\left[\mathrm{Mn}\left({ }^{12} \mathrm{CO}\right)_{4}\left(a_{x}{ }^{13} \mathrm{CO}\right)\left(\mathrm{R}_{\mathrm{F}}\right)\right]$ isotopomers and in the unambiguous assignment of several observed weak bands. The experimental determination of the homolytic $\mathrm{Mn}-\mathrm{R}_{\mathrm{F}}$ bond cleavage activation parameters for 7 as well as for the well-known analogues with $R_{F}$ $=\mathrm{CF}_{3}(5)$ and $\mathrm{CHF}_{2}(\mathbf{6})$, carried out by saturation kinetics with trapping by TTMSS, gave values in close agreement with recent DFT estimations ${ }^{[18]}$ but significantly higher than previous determinations by other experimental methods. ${ }^{[35-36]}$ The aptitude of these complexes to release fluoroalkyl radicals in solution was demonstrated by the successful initiation of the radical polymerization of VDF using compound $\mathbf{5}$, which is the member with the strongest $\mathrm{Mn}-\mathrm{R}_{\mathrm{F}}$ bond. The PVDF was obtained in good yields both under thermal conditions in the dark at $100^{\circ} \mathrm{C}$ (but not at $50{ }^{\circ} \mathrm{C}$ ) and under photochemical conditions (visible or ultraviolet light) at moderate temperatures $\left(40-50^{\circ} \mathrm{C}\right)$. These results rationalize the lack of accumulation of $\left[\mathrm{Mn}(\mathrm{CO})_{5}(\mathrm{PVDF})\right]$ dormant species in the recently reported iodine transfer polymerization of VDF assisted by $\left[\mathrm{Mn}_{2}(\mathrm{CO})_{10}\right]^{\left[{ }^{[12]}\right.}$

\section{Experimental Section}

General. All operations were carried out under an atmosphere of argon except for the purifications by column chromatography, which were carried out in air, and for the sublimations and polymerizations (under vacuum, products collected in air).

Materials. Compounds $\left[\mathrm{Mn}_{2}(\mathrm{CO})_{10}\right] \quad(98 \%$, Strem Chemicals), trifluoroacetic anhydride (ReagentPlus ${ }^{\circledR}$ grade, $\geq 99 \%$, Sigma-Aldrich), difluoroacetic acid (98\%, Fluorochem), 3,3,3-trifluoropropionyl chloride (98\%, Fluorochem), 1-lodo-2,2,2-trifluoroethane (97\%, Fluorochem), 2,2difluoropropionic acid (98\%, Fluorochem), $\mathrm{P}_{2} \mathrm{O}_{5}$ ( $\geq 98 \%$, Fluka), $(2,2,6,6-$ tetramethylpiperidin-yl)oxy (TEMPO, 98\%, Acros Organics), tris(trimethylsilyl)silane (TTMSS, 97\%, Sigma-Aldrich), hexafluorobenzene (99\%, Aldrich), benzene- $\mathrm{D}_{6}\left(99.5 \% \mathrm{D}\right.$, Euriso-top), acetone- $\mathrm{D}_{6}(99.5 \% \mathrm{D}$, Eurisotop), DMSO-D 6 (99.5\%D, Euriso-top), DMF-D7 (99.5\%D, Euriso-top), dimethyl carbonate ( $\geq 99 \%$, Merck $\mathrm{KGaA})$ and silica $(40-63 \mu \mathrm{m}$, VMR 
Chemicals) were used as received. Potassium (98\%, Aldrich) and sodium $(\geq 99.8 \%$, Aldrich) were washed in $n$-pentane to remove the mineral oil prior to use. Laboratory Reagent grade $(\geq 99.5 \%)$ diethyl ether, $n$-pentane and THF were purchased from Sigma-Aldrich. THF was purified by percolation through a dry activated alumina column. Thionyl chloride (ReagentPlus ${ }^{\circledR}$ grade, $\geq 99 \%$, Sigma-Aldrich) was distilled in the presence of sulphur prior to use. VDF was kindly supplied by Arkema and used as received. Difluoroacetic anhydride (from difluoroacetic acid and $\left.\mathrm{P}_{2} \mathrm{O}_{5}\right)^{[49]}$ and 2,2 difluoropropionyl chloride (from 2,2-difluoropropionic acid and oxalyl chloride)[50] were synthesized as described in the literature. The preparations of compounds $\left[\mathrm{Mn}\left(\mathrm{COCF}_{3}\right)(\mathrm{CO})_{5}\right], \quad\left[\mathrm{Mn}\left(\mathrm{CF}_{3}\right)(\mathrm{CO})_{5}\right]$, $\left[\mathrm{Mn}(\mathrm{COCHF})_{2}(\mathrm{CO})_{5}\right]$, and $\left[\mathrm{Mn}\left(\mathrm{CHF}_{2}\right)(\mathrm{CO})_{5}\right]$, were adapted from the literature procedures: ${ }^{[19]}$ purifications were carried out by column chromatography through a silica column, using $n$-pentane as the mobile phase to eliminate the $\left[\mathrm{Mn}_{2}(\mathrm{CO})_{10}\right]$ impurity and then a $1: 9$ diethyl ether/pentane mixture to elute the product. Single crystals of $\left[\mathrm{Mn}\left(\mathrm{COCF}_{3}\right)(\mathrm{CO})_{5}\right], \quad\left[\mathrm{Mn}\left(\mathrm{CF}_{3}\right)(\mathrm{CO})_{5}\right], \quad\left[\mathrm{Mn}\left(\mathrm{COCHF}_{2}\right)(\mathrm{CO})_{5}\right], \quad\left[\mathrm{Mn}\left(\mathrm{CHF}_{2}\right)-\right.$ $\left.(\mathrm{CO})_{5}\right]$ and $\left[\mathrm{Mn}\left(\mathrm{CH}_{2} \mathrm{CF}_{3}\right)(\mathrm{CO})_{5}\right]$ for the X-ray diffraction analysis were grown by sublimation at $50{ }^{\circ} \mathrm{C}$ and 100 mbar. Single crystals of $\left[\mathrm{Mn}\left(\mathrm{COCF}_{2} \mathrm{CH}_{3}\right)(\mathrm{CO})_{5}\right]$ were obtained directly in the flask after the evaporation of the solvent in a rotary evaporator.

Instrumentation. The Nuclear Magnetic Resonance (NMR) spectra were recorded on a Bruker Avance III HD $400 \mathrm{MHz}$ spectrometer. The instrumental parameters for recording spectra were as follows: ${ }^{1} \mathrm{H}$ NMR: flip angle $30^{\circ}$, acquisition time $5.7 \mathrm{~s}$, pulse delay $2 \mathrm{~s}$, number of scans 64 , and a pulse width of $3.05 \mu \mathrm{s} ;{ }^{19} \mathrm{~F}$ NMR: flip angle $30^{\circ}$, acquisition time $2 \mathrm{~s}$, pulse delay $2 \mathrm{~s}$, number of scans 64 , and a pulse width of $3.76 \mu \mathrm{s} ;{ }^{13} \mathrm{C}$ NMR: flip angle $30^{\circ}$, acquisition time $1.5 \mathrm{~s}$, pulse delay $2 \mathrm{~s}$, number of scans 10240 , and a pulse width of $3.27 \mu \mathrm{s}$. The probe has a lower background ${ }^{19} \mathrm{~F}$ NMR signals compared to standard dual-channel probes. The NMR properties for all compounds are reported in Table 1 and the individual spectra are shown in the SI (part A). For the homolytic Mn-R Bond cleavage experiments, the temperature of the NMR probe was calibrated using ethylene glycol and is believed to be accurate to $\pm 0.05^{\circ} \mathrm{C}$. The Fourier transform infrared (FTIR) spectra on the pentane solutions were recorded in transmission mode with a PerkinElmer Spectrum One FT-IR Spectrophotometer using a $\mathrm{CaF}_{2}$ window with a $0.05 \mathrm{~mm}$ optical path length. The IR properties in the $\mathrm{CO}$ stretching region for all compounds are collected in Table 3 and the individual spectra are shown in the $\mathrm{SI}$ (part C). The elemental analyses were carried out by the analytical service of the LCC-Toulouse using a PerkinElmer $2400 \mathrm{CHNS/O} \mathrm{Series} \mathrm{II}$ System (100V). The apparent number average molar masses and dispersity $(\Theta)$ of the synthesized polymers were determined using a Varian 390-LC gel permeation chromatography (GPC) system equipped with differential refractive index (RI), light scattering (LS) and viscosity detectors using a guard column (Varian Polymer Laboratories PLGel 5 $\mu \mathrm{m}$, $50 \times 7.5 \mathrm{~mm}$ ) and two ResiPore columns of the same type. The mobile phase was DMF with $0.1 \%$ wt $\mathrm{LiBr}$ adjusted at a flow rate of $1 \mathrm{~mL} \mathrm{~min}-1$ while the columns were thermostated to $70{ }^{\circ} \mathrm{C}$. The GPC system was calibrated using narrow poly (methyl methacrylate) (PMMA) standards ranging from 550 to $1,568,000 \mathrm{~g} \mathrm{~mol}^{-1}$ (EasiVial- Agilent).

Synthesis of 3,3,3-trifluoropropanoyl(pentacarbonyl)manganese, 3 . In a Schlenk tube, liquid "NaK" alloy was prepared from $395 \mathrm{mg}$ (10.1 $\mathrm{mmol})$ of metallic potassium and $260 \mathrm{mg}(11.3 \mathrm{mmol})$ of metallic sodium under argon. A solution of dimanganese decacarbonyl $(3.00 \mathrm{~g}, 7.69 \mathrm{mmol})$ in $30 \mathrm{~mL}$ of dry THF was added and the resulting mixture was stirred for 3 $\mathrm{h}$ at room temperature, with IR monitoring to verify the completion of the reduction process. The mixture was filtered through Celite to yield a greenish-brown solution, rinsing the Celite with $10 \mathrm{~mL}$ of dry THF. Then, 3,3,3-trifluoropropanoyl chloride $(2.25 \mathrm{~g}, 15.36 \mathrm{mmol})$ was added dropwise at room temperature, generating a light red solution, which subsequently turned bright red and finally orange after $1 \mathrm{~h}$. After additional stirring at room temperature (total $3 \mathrm{~h}$ ), the solvent was evaporated under reduced pressure and the product was purified by column chromatography. A lightyellow band was collected, followed by evaporation to dryness under reduced pressure to afford the product as a pale-yellow solid (3.56 g, 11.5 mmol, yield $75 \%)$. Anal. \% calcd. for $(\mathrm{CO})_{5} \mathrm{Mn}\left(\mathrm{COCH}_{2} \mathrm{CF}_{3}\right), \mathrm{C}_{8} \mathrm{H}_{2} \mathrm{~F}_{3} \mathrm{MnO}_{6}$, C, 31.40; $\mathrm{H}, 0.66$. Found, $\mathrm{C}, 31.5 ; \mathrm{H}, 0.1$.

Synthesis of 2,2,2-trifluoroethyl(pentacarbonyl)manganese, 7 . Compound [(CO) $\left.)_{5 n}\left(\mathrm{COCH}_{2} \mathrm{CF}_{3}\right)\right](2.25 \mathrm{~g}, 7.35 \mathrm{mmol})$ was introduced in a two-neck flask connected to a reflux condenser to avoid any sublimation losses. The flask was then heated under normal pressure to $70^{\circ} \mathrm{C}$ for 1.5 h. During this time, the solid that accumulated at the bottom of the condenser was periodically removed and dropped back to the warm flask bottom. The resulting light-brown powder was purified by column chromatography, yielding the product as a yellow solid $(1.63 \mathrm{~g}, 5.86 \mathrm{mmol}$, yield $80 \%$ ). A single crystal for the $\mathrm{X}$-ray diffraction analysis was obtained by sublimation at $55{ }^{\circ} \mathrm{C}$ and $100 \mathrm{mbar}$. The decarbonylation of $\left[(\mathrm{CO})_{5} \mathrm{Mn}\left(\mathrm{COCH}_{2} \mathrm{CF}_{3}\right)\right]$ could also be accomplished by heating the solid in a sublimation apparatus under vacuum at $55^{\circ} \mathrm{C}$ under 100 mbar for 5 days. Starting the reaction from $1.978 \mathrm{~g}$ of manganese carbonyl $(5.07 \mathrm{mmol})$ and $1.473 \mathrm{~g}$ of 3,3,3-trifluoropropanoyl chloride $(10.06 \mathrm{mmol})$ and following the same synthetic procedure, the pure product $(1.122 \mathrm{~g}, 4.04 \mathrm{mmol}$, yield $40 \%$ ) was directly collected as a light yellow microcrystalline powder from the cold finger. Anal. \% calcd. for $(\mathrm{CO})_{5} \mathrm{Mn}\left(\mathrm{CH}_{2} \mathrm{CF}_{3}\right), \mathrm{C}_{7} \mathrm{H}_{2} \mathrm{~F}_{3} \mathrm{MnO}_{5}, \mathrm{C}$, $30.24 ; \mathrm{H}, 0.73$. Found, $\mathrm{C}, 30.54 ; \mathrm{H}, 0.83$.

Synthesis of 2,2-difluoropropanoyl(pentacarbonyl)manganese, 4. The procedure was similar to that described above for the synthesis of compound 3, using $\mathrm{K}(400 \mathrm{mg}, 10.23 \mathrm{mmol}), \mathrm{Na}(300 \mathrm{mg}, 13.05 \mathrm{mmol})$, $\left[\mathrm{Mn}_{2}(\mathrm{CO})_{10}\right](3.00 \mathrm{~g}, 7.69 \mathrm{mmol})$, dry THF $(30 \mathrm{~mL})$, and 2,2difluoropropanoyl chloride $(1.98 \mathrm{~g}, 15.45 \mathrm{mmol})$. The latter was produced in situ as follows. 2,2-Difluoropropionic acid $(1.70 \mathrm{~g}, 15.45 \mathrm{mmol})$ was introduced in $50 \mathrm{~mL}$ two-neck flask connected to a bubbler and dissolved in $5 \mathrm{~mL}$ of dry THF. Then oxalyl chloride $(2.11 \mathrm{~g}, 16.62 \mathrm{mmol})$ was added dropwise and finally $150 \mu \mathrm{L}$ of dry DMF was added. The mixture was stirred for $1 \mathrm{~h}$ (until bubbling stopped). The resulting 2,2-difluoropropanoyl chloride solution was directly added dropwise to the $\mathrm{K}\left[\mathrm{Mn}(\mathrm{CO})_{5}\right]$ solution at room temperature. The initially clear orange solution turned cloudy and yellow within a few minutes. After stirring at room temperature for $3 \mathrm{~h}$, the solvent was evaporated under reduced pressure. The product work-up procedure was the same as for the synthesis of $\left[(\mathrm{CO})_{5} \mathrm{Mn}\left(\mathrm{COCH}_{2} \mathrm{CF}_{3}\right)\right]$. The light-yellow (nearly colorless) band collected after the $\left[\mathrm{Mn}_{2}(\mathrm{CO})_{10}\right]$ removal yielded the product as volatile brownish-white needle-shape microcrystals after solvent evaporation $(1.49 \mathrm{~g}, 5.17 \mathrm{mmol}$, yield $33 \%)$. A third fraction of an orange unidentified oil was recovered immediately after that of the product. Anal. \% calcd. for $\left[(\mathrm{CO})_{5} \mathrm{Mn}\left(\mathrm{COCF}_{2} \mathrm{CH}_{3}\right)\right], \mathrm{C}_{8} \mathrm{H}_{3} \mathrm{~F}_{2} \mathrm{MnO}_{6}$, C, 33.36; $\mathrm{H}, 1$.05. Found, C, 33.9; $\mathrm{H}, 0.7$.

Synthesis of 1,1-difluoroethyl(pentacarbonyl)manganese, 8. Compound [(CO) $\left.\mathrm{Mn}\left(\mathrm{COCF}_{2} \mathrm{CH}_{3}\right)\right](20 \mathrm{mg}, 0.069 \mathrm{mmol})$ was introduced in a $50 \mathrm{~mL}$ two-neck flask and dissolved in $5 \mathrm{~mL}$ of 2-butanone. The system was connected to a refrigerant and to a bubbler and purge for $15 \mathrm{~min}$ with an argon flow. Then it was heated up to $80^{\circ} \mathrm{C}$ for $1 \mathrm{~h}$. The solvent was finally removed by evaporation under reduced pressure leading to a yellow powder which contain the complex 8 (yield 64\%, determined by relative integration of $\left[(\mathrm{CO})_{5} \mathrm{Mn}\left(\mathrm{COCF}_{2} \mathrm{CH}_{3}\right)\right]$ and $\left[(\mathrm{CO})_{5} \mathrm{Mn}_{2}\left(\mathrm{CF}_{2} \mathrm{CH}_{3}\right)\right]$ signals). The small amount obtained after decarbonylation reaction did not allow its purification by column chromatography. Additional experiments carried out with a greater amount of complex and heating for a longer period let to decomposition of the desired product and lower spectroscopic yields.

Investigation of the Homolytic Mn-R Bond Cleavage. All experiments were carried out using the same procedure. As a representative example, $\left[(\mathrm{CO})_{5} \mathrm{Mn}\left(\mathrm{CF}_{3}\right)\right]$ (159.3 mg, $\left.0.60 \mathrm{mmol}\right)$ was dissolved in $5.0 \mathrm{~mL}$ of $\mathrm{C}_{6} \mathrm{D}_{6}$ together with 8 drops of $\mathrm{C}_{6} \mathrm{~F}_{6}$ as internal standard. Aliquots of this solution $(0.4 \mathrm{~mL})$ were transferred into NMR tubes, then the desired amount of (TMS) ${ }_{3} \mathrm{SiH}$ was added and the thermal decomposition was monitored at the desired temperatures by ${ }^{19} \mathrm{~F}$ NMR. The signal of hexafluorobenzene (internal standard) is integrated from $-162.8 \mathrm{ppm}$ to $-163.2 \mathrm{ppm}$, and the value of the internal standard was set to 1 in all the spectra. Then the complex signal was integrated from $7.7 \mathrm{ppm}$ to $8.1 \mathrm{ppm}$. Knowing the initial concentration of complex in each tube $\left(\mathrm{C}_{0}\right)$, the concentration of complex 
at time $t\left(\mathrm{C}_{t}\right)$ was determined by the as $C_{t}=C_{0} t_{t} / l_{0}$, where $I_{0}$ and $I_{t}$ stand for the integral value of the NMR signal of the complex at $t=0$ and at $t$, respectively. The $\ln \left[\mathrm{C}_{0} / \mathrm{C}_{t}\right]$ vs time plots led to straight lines, the slopes of which represents k (Figures S.E3.1- Figure S.E3.3).

VDF polymerizations with trifluoromethyl(pentacarbonyl)manganese The radical polymerizations of VDF were carried out in thick-walled $12 \mathrm{~mL}$ Carius tubes in which the solvent ( $5 \mathrm{~mL}$ of dimethyl carbonate) and $\left[(\mathrm{CO})_{5} \mathrm{Mn}\left(\mathrm{CF}_{3}\right)\right]$ (128 mg, $0.48 \mathrm{mmol}$ ) were added. The resulting solutions were then degassed by performing three freeze-pump-thaw cycles. Then, the gaseous VDF monomer $(1.5 \mathrm{~g}, 23.4 \mathrm{mmol})$ was transferred into the Carius tube, which was cooled at the liquid nitrogen temperature, using a custom-made manifold that enables the accurate measurement of the gas quantity (using "pressure drop vs mass of monomer" calibration curve). The tube was then sealed under static vacuum at the liquid nitrogen temperature. For the thermal activation experiments, the tube was placed horizontally in a thermostatic shaking water bath while for the visible light activation experiment, it was placed horizontally in a tube roller shaker with
3 LED bulbs (Diall 1102270698, $14 \mathrm{~W}, 1521 \mathrm{Im}$ ), radiating from above, placed at $2 \mathrm{~cm}$ from the tube. The proximity of the bulbs caused the tube to warm up to ca. $40^{\circ} \mathrm{C}$. For the UV activation experiment, the tube was equipped with a small magnetic stirring bar and stirred vertically in a Rayonet RPR-200 UV reactor equipped with sixteen $300 \mathrm{~nm}$ wavelength UV-lamps of $35 \mathrm{~W}$ each. Despite the fan placed inside the UV chamber, the heat generated by the UV lamps caused the tube to warm up to ca. $50^{\circ} \mathrm{C}$. After $24 \mathrm{~h}$, each tube was frozen into liquid nitrogen, opened, and the solvent was evaporated in a rotary evaporator. The resulting polymers were dissolved in deuterated DMF and analyzed by ${ }^{1} \mathrm{H}$ and ${ }^{19} \mathrm{~F}$ NMR spectroscopies. The molar masses and dispersities were determined by SEC chromatography in DMF (refractive index, calibrated with PMMA standards).

Table 6. Crystal and refinement parameters for all compounds investigated by X-ray diffraction.

\begin{tabular}{|c|c|c|c|c|c|c|}
\hline Identification code & 1 & 2 & 4 & 5 & 6 & 7 \\
\hline Empirical formula & $\mathrm{C}_{7} \mathrm{~F}_{3} \mathrm{MnO}_{6}$ & $\mathrm{C}_{7} \mathrm{HF}_{2} \mathrm{MnO}_{6}$ & $\mathrm{C}_{8} \mathrm{H}_{3} \mathrm{~F}_{2} \mathrm{MnO}_{6}$ & $\mathrm{C}_{6} \mathrm{~F}_{3} \mathrm{MnO}_{5}$ & $\mathrm{C}_{6} \mathrm{HF}_{2} \mathrm{MnO}_{5}$ & $\mathrm{C}_{7} \mathrm{H}_{2} \mathrm{~F}_{3} \mathrm{MnO}_{5}$ \\
\hline Formula weight & 292.01 & 274.02 & 288.04 & 264.91 & 246.01 & 278.03 \\
\hline Temperature, $\mathrm{K}$ & $173(4)$ & $180(2)$ & $173(2)$ & $173(2)$ & $173(2)$ & $173(2)$ \\
\hline Wavelength, $\AA$ & 0.71073 & 0.71073 & 0.71073 & 0.71073 & 0.71073 & 0.71073 \\
\hline Crystal system & Orthorhombic & Orthorhombic & Monoclinic & Monoclinic & Orthorhombic & Monoclinic \\
\hline Space group & $\mathrm{Pna2}_{1}$ & $\mathrm{Pna2}_{1}$ & $\mathrm{P} 2_{1} / \mathrm{c}$ & $\mathrm{P} 21 / \mathrm{m}$ & Pnma & $\mathrm{P} 2{ }_{1} / \mathrm{n}$ \\
\hline $\mathrm{a}, \AA$ & $14.4714(4)$ & $14.0916(7)$ & $14.6140(10)$ & $6.3579(4)$ & $12.2397(3)$ & $11.6543(7)$ \\
\hline $\mathrm{b}, \AA$ & $10.8047(4)$ & $10.8226(7)$ & $6.2155(4)$ & $11.0117(6)$ & $10.7284(2)$ & $6.8405(4)$ \\
\hline$\alpha, \circ$ & 90.0 & 90.0 & 90.0 & 90.0 & 90.0 & 90.0 \\
\hline 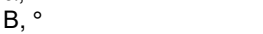 & 90.0 & 90.0 & $106.608(2)$ & $107.459(2)$ & 90.0 & $\square=96.288(5)$ \\
\hline$\gamma{ }^{\circ}$ & 90.0 & 90.0 & 90.0 & 90.0 & 90.0 & 90.0 \\
\hline Volume, $\AA^{3}$ & $997.23(6)$ & $964.84(9)$ & $1082.00(13)$ & $438.48(5)$ & $826.66(3)$ & 1924.3(2) \\
\hline Z & 4 & 4 & 4 & 2 & 4 & 8 \\
\hline Density (calc), $\mathrm{Mg} / \mathrm{m}^{3}$ & 1.945 & 1.886 & 1.768 & 2.000 & 1.977 & 1.919 \\
\hline Abs. coefficient, $\mathrm{mm}^{-1}$ & 1.384 & 1.409 & 1.261 & 1.768 & 1.623 & 1.421 \\
\hline$F(000)$ & 568 & 536 & 568 & 256 & 480 & 1088 \\
\hline Crystal size, $\mathrm{mm}^{3}$ & $0.38 \times 0.25 \times 0.20$ & $0.32 \times 0.25 \times 0.14$ & $0.20 \times 0.12 \times 0.05$ & $0.38 \times 0.32 \times 0.20$ & $0.37 \times 0.32 \times 0.2$ & $0.50 \times 0.20 \times 0.13$ \\
\hline Indpt reflections $\left(\mathrm{R}_{\mathrm{int}}\right)$ & $2006(0.0257)$ & $1777(0.0326)$ & $3169(0.0317)$ & $1021(0.0299)$ & $890(0.0733)$ & $3934(0.0232)$ \\
\hline Completeness, \% & 99.5 & $99.1<-1$ & 100.0 & 99.9 & 99.8 & 99.4 \\
\hline Absorption correction & Multi-scan & Multi-scan & Multi-scan & Multi-scan & Multi-scan & Multi-scan \\
\hline $\begin{array}{l}\text { Max. / min. Transm. } \\
\text { Refinement method }\end{array}$ & $\begin{array}{l}1.0 / 0.944 \\
F^{2}\end{array}$ & $\begin{array}{l}1.0 / 0.669 \\
F^{2}\end{array}$ & $\begin{array}{l}0.7476 / 0.6021 \\
F^{2}\end{array}$ & $\begin{array}{l}0.7461 / 0.5264 \\
F^{2}\end{array}$ & $\begin{array}{l}0.7457 / 0.6876 \\
F^{2}\end{array}$ & $\begin{array}{l}1.0 / 0.787 \\
F^{2}\end{array}$ \\
\hline Data /restraints/param. & $2006 / 38$ / 212 & $1777 / 1 / 145$ & $3169 / 0 / 155$ & $1021 / 0 / 76$ & $890 / 0 / 88$ & 3934 / 0 / 289 \\
\hline Goodness-of-fit on $F^{2}$ & 1.029 & 1.119 & 1.159 & 1.158 & 1.145 & 1.092 \\
\hline $\mathrm{R} 1, \mathrm{wR} 2[\mathrm{l}>2 \sigma(\mathrm{I})]$ & $0.0223,0.0467$ & $0.0405,0.1090$ & $0.0254,0.0734$ & $0.0254,0.0640$ & $0.0248,0.0667$ & $0.0279,0.0630$ \\
\hline R1, wR2 (all data) & $0.0250,0.0477$ & $0.0419,0.1107$ & $0.0301,0.0869$ & $0.0264,0.0647$ & $0.0254,0.0674$ & $0.0341,0.0662$ \\
\hline Flack's parameter & $0.067(12)$ & $0.01(3)$ & & & & \\
\hline Residual density, e. $\AA^{-3}$ & $0.224 /-0.172$ & $0.947 /-0.853$ & $0.686 /-0.450$ & $0.493 /-0.582$ & $0.516 /-0.582$ & $0.323 /-0.279$ \\
\hline
\end{tabular}

X-ray crystallography. A single crystal of each compound was mounted under inert perfluoropolyether on the tip of a glass fibre and cooled in the cryostream of either a Rigaku Oxford-Diffraction Gemini EOS diffractometer (for 1, 2 and 7) or a Bruker APEXII diffractometer (for 4, 5 and $\mathbf{6 )}$. The structures were solved by using the integrate space-group and crystal structure determination SHELXT software ${ }^{[51]}$ and refined by leastsquares procedures on $F^{2}$ using SHELXL-2014. ${ }^{[52]}$ The crystal and refinement parameters of all compounds are collected in Table 6 and the full list of bond distances and angles provided in SI tables (section S.B). When present, the $\mathrm{H}$ atoms attached to carbon atoms were introduced in the calculations at idealized positions and treated with the riding model, except for compound 6 where, because of a disorder affecting the $\mathrm{CHF}_{2}$ group, the $\mathrm{H}$ atom position was refined. In three of the six compounds, namely 1,2 and 6 , the fluorinated organic fragments show positional disorder. In compound $\mathbf{1}$, the $\mathrm{CF}_{3}$ group is disordered by free rotation around the $\mathrm{C} 6-\mathrm{C} 7$ bond. To model the disorder, three different orientations were refined using the PART and SUMP instructions to constrain the sum of the occupancy factors, which refined to $0.46,0.28$ and 0.26 , to be equal to 1 . In compound 2, the $\mathrm{CHF}_{2}$ moiety is disordered over two positions by a ca. $36^{\circ}$ rotation around the $\mathrm{C} 1-\mathrm{C} 11$ bond. To model this disorder, the PART and restrain instructions (SADI) were used. In compound 6 , the mirror plane $\mathrm{m}(\mathrm{x}, 1 / 4, \mathrm{z})$ containing the $\mathrm{Mn} 1, \mathrm{C} 2, \mathrm{O} 2, \mathrm{C} 3$ and $\mathrm{O} 3$ atoms makes the $\mathrm{CHF}_{2}$ group and a $\mathrm{CO}$ ligand share the same two sites. The absolute structures for $\mathbf{1}$ and $\mathbf{2}$ were determined by refining the Flack parameter ${ }^{[53]}$ The drawings of the molecules were realised with the help of ORTEP32. ${ }^{[54]}$ Crystallographic data (excluding structure factors) have been deposited with the Cambridge Crystallographic Data Centre as supplementary publication no. CCDC 1851284-1851288. Copies of the data can be obtained free of charge on application to the Director, CCDC, 12 Union Road, Cambridge CB2 1EZ, UK (fax: (+44) 1223-336-033; email: deposit@ccdc.cam.ac.uk).

Computational Details. The IR spectra of compounds 5-8 were computed using the Gaussian09 suite of programs, ${ }^{[5]}$ using the previously optimized 
geometries. The same level of theory previously used for the geometry optimization (BPW91* functional;; ${ }^{[56]} 6-31 \mathrm{G}(\mathrm{d}, \mathrm{p})$ basis functions for all light atoms $(\mathrm{H}, \mathrm{C}, \mathrm{F}, \mathrm{O}, \mathrm{S})$ and $\mathrm{SDD}$ basis set augmented by an $\mathrm{f}$ polarization function $(\alpha=2.195)$ for the $\mathrm{Mn}$ atom $\left.{ }^{[57]}\right)$ was adopted for the ffrequency calculations for all isotopomers (see text).

\section{Acknowledgements}

This work was supported by the Agence Nationale de la Recherche (ANR, French National Agency) through the project FLUPOL (grant No. ANR-14-CE07-0012). We also gratefully acknowledge additional financial support from the Centre National de la Recherche Scientifique (CNRS). We thank Arkema (Pierre Bénite, France) for supplying free sample of VDF and Mr. Cédric Totée and Pr. Gilles Silly for their help in NMR spectroscopy. This work was granted access to the HPC resources of IDRIS under the allocation 2016-086343 made by GENCI (Grand Équipement National de Calcul Intensif) and to the resources of the CICT (Centre Interuniversitaire de Calcul de Toulouse, project CALMIP).

Keywords: bond dissociation enthalpy • fluoroalkyl radicals • manganese $\bullet$ radical polymerization $\bullet$ vinylidene fluoride

[1] R. D. Closson, J. Kozikowski and T. H. Coffield, J. Org. Chem. 1957, 22, 598-598.

[2] a) T. H. Coffield, J. Kozikowski and R. D. Closson, J. Org. Chem. 1957, 22, 598-598; b) F. Calderazzo and F. A. Cotton, Inorg. Chem. 1962, 1, 30-36.

[3] R. H. Crabtree, The Organometallic Chemistry of the Transition Metals, Wiley-Interscience, New York, 2005.

[4] W. Beck, W. Hieber and H. Tengler, Chem. Ber. 1961, 94, 862-872.

[5] a) T. H. Coffield, J. Kozikowski and R. D. Closson, Abstracts of the International Conference on Coordination Chemistry, London April 1959, 126; b) H. D. Kaesz, R. B. King and F. G. A. Stone, Z. Naturforsch. B 1960, 15, 763-764.

[6] a) F. Calderazzo, K. Noack and U. Schaerer, J. Organomet. Chem. 1966, $6,265-271$; b) K. Noack, U. Schaerer and F. Calderazzo, J. Organometal. Chem. 1967, 8, 517-526.

[7] D. Naumann and M. Kaiser, Z. Anorg. Allg. Chem. 1995, 621, 812-816.

[8] a) X. Ma, Z. Zuo, G. Liu and Z. Huang, ACS Omega 2017, 2, 4688-4692; b) D. A. Valyaev, D. Wei, S. Elangovan, M. Cavailles, V. Dorcet, J.-B. Sortais, C. Darcel and N. Lugan, Organometallics 2016, 35, 4090-4098 c) S. Vijjamarri, V. K. Chidara and G. Du, ACS Omega 2017, 2, 582-591.

[9] a) N. Duc Hanh, X. Trivelli, F. Capet, J.-F. Paul, F. Dumeignil and R. M. Gauvin, ACS Catal. 2017, 7, 2022-2032; b) B. Dutta, V. Sharma, N Sassu, Y. Dang, C. Weerakkody, J. Macharia, R. Miao, A. R. Howell and S. L. Suib, Green Chem. 2017, 19, 5350-5355; c) N. A. Espinosa-Jalapa, A. Kumar, G. Leitus, Y. Diskin-Posner and D. Milstein, J. Am. Chem. Soc. 2017, 139, 11722-11725.

[10] W. Liu and L. Ackermann, ACS Catal. 2016, 6, 3743-3752.

[11] D. Zell, U. Dhawa, V. Mueller, M. Bursch, S. Grimme and L. Ackermann, ACS Catal. 2017, 7, 4209-4213.

[12] a) A. D. Asandei, O. I. Adebolu and C. P. Simpson, J. Am. Chem. Soc. 2012, 134, 6080-6083; b) C. P. Simpson, O. I. Adebolu, J.-S. Kim, V. Vasu and A. D. Asandei, Macromolecules 2015, 48, 6404-6420.

[13] a) M. Tatemoto, Int. Polym. Sci. Tech. 1985, 12, 85-98; b) G. David, C. Boyer, J. Tonnar, B. Améduri, P. Lacroix-Desmazes and B. Boutevin, Chem. Rev. 2006, 106, 3936-3962; c) S. Banerjee, Y. Patil, T. Ono and B. Améduri, Macromolecules 2017, 50, 203-214.

[14] a) M. A. Bachmann, W. L. Gordon, J. L. Koenig and J. B. Lando, Journal of Applied Physics 1979, 50, 6106-6112; b) D. E. Mattern, F. T. Lin and D. M. Hercules, Analytical Chemistry 1984, 56, 2762-2769; c) A. J. Lovinger, D. D. Davis, R. E. Cais and J. M. Kometani, Polymer 1987, 28, 617-626; d) P. Pladis, A. H. Alexopoulos and C. Kiparissides, Ind. Engin. Chem. Res. 2014, 53, 7352-7364.
[15] A. D. Asandei, Chem. Rev. 2016, 116, 2244-2274.

[16] a) R. Poli, Angew. Chem. Int. Ed. 2006, 45, 5058-5070; b) R. Poli in Organometallic Mediated Radical Polymerization, Vol. 3 Eds.: K. Matyjaszewski and M. Möller), Elsevier BV, Amsterdam, 2012, pp. 351375; c) R. Poli, Chem. Eur. J. 2015, 21, 6988-7001.

[17] a) J. Demarteau, B. Améduri, V. Ladmiral, M. A. Mees, R. Hoogenboom, A. Debuigne and C. Detrembleur, Macromolecules 2017, 50, 3750-3760; b) S. Banerjee, E. V. Bellan, F. Gayet, A. Debuigne, C. Detrembleur, R. Poli, B. Améduri and V. Ladmiral, Polymers 2017, 9, 802; c) S. Banerjee, V. Ladmiral, A. Debuigne, C. Detrembleur, S. M. W. Rahaman, R. Poli and B. Améduri, Macromol. Rapid Commun. 2017, 38, 1700203; d) S. Banerjee, V. Ladmiral, A. Debuigne, C. Detrembleur, R. Poli and B. Améduri, Angew. Chem. Int. Ed. 2018, 57, 2934-2937.

[18] R. Poli, S. M. W. Rahaman, V. Ladmiral and B. Améduri, J. Organomet. Chem. 2018, 864, 12-18

[19] a) R. B. King in Alkyl, Acyl and perfluoroalkyl metal carbonyls, Vol. 1 Academic Press, NY, 1965, pp. 145-147; b) R. B. King, Acc. Chem. Res. 1970, 3, 417-427.

[20] J. E. Ellis and E. A. Flom, J. Organomet. Chem. 1975, 99, 263-268.

[21] a) R. B. King, .J. Inorg. Nucl. Chem. 1963, 25, 1296-1298; b) J. J. Eisch and R. B. King, Organometallic syntheses, Academic Press, New York and London, 1965; c) R. B. King and F. G. A. Stone, Inorg. Synth. 1963, 7, 196-201.

[22] F. Calderazzo, E. A. C. Lucken and D. F. Williams, J. Chem. Soc. A 1967, 154-158.

[23] S. Evans, J. C. Green, M. L. H. Green, A. F. Orchard and D. W. Turner, Discussions of the Faraday Society 1969, 112-120.

[24] a) F. W. Einstein, H. Luth and J. Trotter, J. Chem. Soc. A 1967, 89-93; b) R. P. Hughes, S. J. Doig, R. C. Hemond, W. L. Smith, R. E. Davis, S M. Gadol and K. D. Holland, Organometallics 1990, 9, 2745-2753; c) D. Lentz and S. Willemsen, Angew. Chem. Int. Ed. 2001, 40, 2087-2091; d) M. F. Kuehnel and D. Lentz, Dalton Trans. 2009, 4747-4755.

[25] A. P. Masters, J. F. Richardson and T. S. Sorensen, Canad. J. Chem. 1990, 68, 2221-2227.

[26] E. Lindner, W. Wassing, R. Fawzi and M. Steimann, Z. Natuforsch. B 1993, 48, 1651-1660.

[27] M. A. Andrews, J. Eckert, J. A. Goldstone, L. Passell and B. Swanson, J. Am. Chem. Soc. 1983, 105, 2262-2269.

[28] B. K. Nicholson, J. S. Mclndoe, D. A. Clemente and W. T. Robinson, Structural Chemistry 2008, 19, 489-492.

[29] F. A. Cotton, A. Musco and G. Yagupsky, Inorg. Chem. 1967, 6, 13571364

[30] S. C. Tenhaeff, K. J. Covert, M. P. Castellani, J. Grunkemeier, C. Kunz, J. R. Weakley, T. Koenig and D. R. Tyler, Organometallics 1993, 12, 5000-5004.

[31] a) R. G. Finke and B. P. Hay, Inorg. Chem. 1984, 23, 3041-3043; b) J. Halpern, S. H. Kim and T. W. Leung, J. Am. Chem. Soc. 1984, 106, 83178319

[32] a) G. N. Schrauzer and J. H. Grate, J. Am. Chem. Soc. 1981, 103, 541546; b) R. J. Blau and J. H. Espenson, J. Am. Chem. Soc. 1985, 107, 3530-3533; c) S. H. Kim, H. L. Chen, N. Feilchenfeld and J. Halpern, J. Am. Chem. Soc. 1988, 110, 3120-3126.

[33] a) A. Goto and T. Fukuda, Macromol. Rapid Commun. 1999, 20, 633 636; b) K. Matyjaszewski, H.-j. Paik, P. Zhou and S. J. Diamanti, Macromolecules 2001, 34, 5125-5131; c) A. K. Nanda and K. Matyjaszewski, Macromolecules 2003, 36, 8222-8224; d) T. Pintauer, W. Braunecker, E. Collange, R. Poli and K. Matyjaszewski, Macromolecules 2004, 37, 2679-2682.

[34] T. J. Meyer and J. V. Caspar, Chem. Rev. 1985, 85, 187-218.

[35] J. A. Connor, M. T. Zafaranimoattar, J. Bickerton, N. I. Elsaied, S. Suradi, R. Carson, G. Altakhin and H. A. Skinner, Organometallics 1982, 1, 1166-1174.

[36] J. A. Martinho Simões and J. L. Beauchamp, Chem. Rev. 1990, 90, 629688.

[37] Y. Zhu, J. Gong and Y. Wan, J. Org. Chem. 2017, 82, 7428-7436.

[38] a) P. Jaitner, W. Huber, G. Huttner and O. Scheidsteger, J. Organomet. Chem. 1983, 259, C1-C5; b) D. Rehder and P. Jaitner, J. Organomet. Chem. 1987, 329, 337-342; c) J. P. Lomont, S. C. Nguyen and C. B. Harris, J. Am. Chem. Soc. 2013, 135, 11266-11273. 
[39] a) C. Chatgilialoglu, D. Griller and M. Lesage, J. Org. Chem. 1988, 53, 3641-3642; b) M. Ballestri, C. Chatgilialoglu, K. B. Clark, D. Griller, B. Giese and B. Kopping, J. Org. Chem. 1991, 56, 678-683.

[40] a) C. Chatgilialoglu, D. Griller and M. Lesage, J. Org. Chem. 1989, 54, 2492-2494; b) C. Chatgilialoglu, J. Dickhaut and B. Giese, J. Org. Chem. 1991, 56, 6399-6403; c) C. Chatgilialoglu, Helv. Chim. Acta 2006, 89, 2387-2398.

[41] M. Ishikawa, A. Nakamura and M. Kumada, J. Organometal. Chem. 1973, 59, C11-C12.

[42] a) B. K. Nicholson and J. Simpson, J. Organometal. Chem. 1971, 32 C29-C30; b) B. K. Nicholson, J. Simpson and W. T. Robinson, J. Organometal. Chem. 1973, 47, 403-412.

[43] D. K. Russell, I. M. T. Davidson, A. M. Ellis, G. P. Mills, M. Pennington, I. M. Povey, J. B. Raynor and S. Saydam, Chem. Vap. Deposition 1998, 4, 103-107.

[44] E. Folga and T. Ziegler, J. Am. Chem. Soc. 1993, 115, 5169-5176.

[45] J. Guiot, B. Ameduri and B. Boutevin, Macromolecules 2002, 35, 86948707.

[46] a) M. Pianca, E. Barchiesi, G. Esposto and S. Radice, J. Fluorine Chem. 1999, 95, 71-84; b) M. Destarac, K. Matyjaszewski, E. Silverman, B. Améduri and B. Boutevin, Macromolecules 2000, 33, 4613-4615; c) E. Girard, J. D. Marty, B. Améduri and M. Destarac, ACS Macro Lett. 2012 1, 270-274; d) N. Golzari, J. Adams and S. Beuermann, Polymers 2017 9.

[47] S. M. Aliwi, C. H. Bamford and S. U. Mullik, J. Polym. Sci., Polym. symp. 1975, 33-50.

[48] a) B. Ameduri, C. Ladaviere, F. Delolme and B. Boutevin, Macromolecules 2004, 37, 7602-7609; b) F. Boschet, T. Ono and B. Ameduri, Macromol. Rapid Comm. 2012, 33, 302-308; c) A. D. Asandei, O. I. Adebolu, C. P. Simpson and J.-S. Kim, Angew. Chem. Int. Ed. 2013, 52, 10027-10030.
[49] E. Sawicki, J. Org. Chem. 1956, 21, 376-376.

[50] B. K. Albrecht, J. E. Audia, L. A. Dakin, M. Duplessis, V. S. Gehling, J.C. Harmange, C. G. Nasveschuk and R. G. Vaswani, WO 2015/023915 A1 2015.

[51] G. M. Sheldrick, Acta Crystallogr. A 2015, 71, 3-8.

[52] G. M. Sheldrick, Acta Crystallogr. C 2015, 71, 3-8.

[53] H. D. Flack, Acta Cryst. 1983, A39, 876-881.

[54] a) M. N. Burnett and C. K. Johnson, ORTEPIII, Report ORNL-6895., Oak Ridge National Laboratory, Oak Ridge, Tennessee, U.S., 1996, p; b) L. J. Farrugia, J. Appl. Cryst. 1997, 30, 565.

[55] M. J. Frisch, G. W. Trucks, H. B. Schlegel, G. E. Scuseria, M. A. Robb, J. R. Cheeseman, G. Scalmani, V. Barone, B. Mennucci, G. A. Petersson, H. Nakatsuji, M. Caricato, X. Li, H. P. Hratchian, A. F. Izmaylov, J. Bloino, G. Zheng, J. L. Sonnenberg, M. Hada, M. Ehara, K. Toyota, R. Fukuda, J. Hasegawa, M. Ishida, T. Nakajima, Y. Honda, O. Kitao, H. Nakai, T. Vreven, J. Montgomery, J. A., J. E. Peralta, F. Ogliaro, M. Bearpark, J. J. Heyd, E. Brothers, K. N. Kudin, V. N. Staroverov, R. Kobayashi, J. Normand, K. Raghavachari, A. Rendell, J. C. Burant, S. S. lyengar, J. Tomasi, M. Cossi, N. Rega, N. J. Millam, M. Klene, J. E. Knox, J. B. Cross, V. Bakken, C. Adamo, J. Jaramillo, R. Gomperts, R. E. Stratmann, O. Yazyev, A. J. Austin, R. Cammi, C. Pomelli, J. W. Ochterski, R. L. Martin, K. Morokuma, V. G. Zakrzewski, G. A. Voth, P. Salvador, J. J. Dannenberg, S. Dapprich, A. D. Daniels, Ö. Farkas, J. B. Foresman, J. V. Ortiz, J. Cioslowski and D. J. Fox, Gaussian 09, Revision D.01, Gaussian, Inc., Wallingford CT, 2009, p

[56] M. Reiher, Inorg. Chem. 2002, 41, 6928-6935.

[57] A. W. Ehlers, M. Böhme, S. Dapprich, A. Gobbi, A. Hoellwarth, V. Jonas, K. F. Koehler, R. Stegmann, A. Veldkamp and G. Frenking, Chem. Phys. Lett. 1993, 208, 111-114. 


\section{FULL PAPER}

$\left[\mathrm{Mn}(\mathrm{CO})_{5}\left(\mathrm{R}_{\mathrm{F}}\right)\right] \quad$ complexes with floroalkyl groups that model PVDF dormant chains, though having a homolytically strong $\mathrm{Mn}-\mathrm{R}_{\mathrm{F}}$ bond, are efficient initiators for the radical polymerization of VDF under thermal and photochemical conditions.

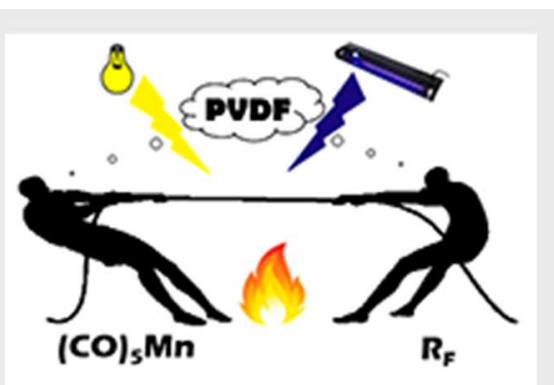

THE KEY IS

\section{IN THE STRENGTH}

Roberto Morales-Cerrada, Christophe Fliedel, Jean-Claude Daran, Florence Gayet, Vincent Ladmiral, Bruno Améduri*, Rinaldo Poli *

\section{Page No. - Page No.}

Fluoroalkyl radical generation by homolytic bond dissociation in pentacarbonylmanganese derivatives 